Open Access

\title{
Prophylactic melatonin significantly reduces Alzheimer's neuropathology and associated cognitive deficits independent of antioxidant pathways in AßPP ${ }^{\text {swe }} / P S 1$ mice
}

\author{
G. O'Neal-Moffitt ${ }^{1 *}$, V. Delic ${ }^{2}$, P. C. Bradshaw ${ }^{2}$ and J. Olcese ${ }^{1}$
}

\begin{abstract}
Background: Alzheimer's disease (AD) underlies dementia for millions of people worldwide, and its occurrence is set to double in the next 20 years. Currently, approved drugs for treating AD only marginally ameliorate cognitive deficits, and provide limited symptomatic relief, while newer substances under therapeutic development are potentially years away from benefiting patients. Melatonin (MEL) for insomnia has been proven safe with $>15$ years of over-the-counter access in the US. MEL exerts multiple complementary mechanisms of action against AD in animal models; thus it may be an excellent disease-modifying therapeutic. While presumed to provide neuroprotection via activation of known G-protein-coupled melatonin receptors (MTNRs), some data indicate MEL acts intracellularly to protect mitochondria and neurons by scavenging reactive oxygen species and reducing free radical formation. We examined whether genetic deletion of MTNRs abolishes MEL's neuroprotective actions in the ABPP ${ }^{\text {swe }}$ /PSEN1dE9 mouse model of $A D$ (2xAD). Beginning at 4 months of age, both $A D$ and control mice either with or without both MTNRs were administered either MEL or vehicle in drinking water for 12 months.
\end{abstract}

Results: Behavioral and cognitive assessments of 15-month-old AD mice revealed receptor-dependent effects of MEL on spatial learning and memory (Barnes maze, Morris Water Maze), but receptor-independent neuroprotective actions of MEL on non-spatial cognitive performance (Novel Object Recognition Test). Similarly, amyloid plaque loads in hippocampus and frontal cortex, as well as plasma $A \beta_{1-42}$ levels, were significantly reduced by MEL in a receptorindependent manner, in contrast to MEL's efficacy in reducing cortical antioxidant gene expression (Catalase, SOD1, Glutathione Peroxidase-1, Nrf2) only when receptors were present. Increased cytochrome c oxidase activity was seen in $16 \mathrm{mo}$ AD mice as compared to non-AD control mice. This increase was completely prevented by MEL treatment of 2XAD/MTNR+ mice, but only partially prevented in 2XAD/MTNR- mice, consistent with mixed receptor-dependent and independent effects of MEL on this measure of mitochondrial function.

Conclusions: These findings demonstrate that prophylactic MEL significantly reduces AD neuropathology and associated cognitive deficits in a manner that is independent of antioxidant pathways. Future identification of direct molecular targets for MEL action in the brain should open new vistas for development of better AD therapeutics.

Keywords: Melatonin, Alzheimer's, Melatonin receptors, Cognition, Mice, Cytochrome c oxidase

\footnotetext{
*Correspondence: gmoffitt@neuro.fsu.edu

'Department of Biomedical Sciences, College of Medicine, Florida State University Program in Neuroscience, 1115 West Call Street, Tallahassee, FL 32306, USA

Full list of author information is available at the end of the article
} 


\section{Background}

Current therapeutics and drugs for improving memory loss in Alzheimer's disease (AD) patients only marginally ameliorate cognitive deficits, and provide patients with only restricted symptomatic relief [1-3]. Many compounds under therapeutic development are years away from benefiting $\mathrm{AD}$ patients. Thus, there is a critical need for rapid development of safe, effective therapeutics against AD. Melatonin analogs may provide such a therapeutic.

Melatonin (MEL) is known to modulate many physiological functions [4-6]. With advancing age and certain age-related diseases, the endogenous secretion of MEL drops markedly, and MEL supplementation can ameliorate sleep disorders in the aged [7]. Declines in blood and CSF MEL levels in Alzheimer disease patients have been reported to parallel the progression of neuropathology $[8,9]$. Although MEL has been given routinely to $A D$ patients to suppress sundowning, few publications have investigated the cognitive effects of MEL administration on AD patients. MEL stabilized cognitive function in AD patients over a 2-3 year period [10] and improved cognitive performance in mild cognitive impairment (MCI) individuals [11]. A 3-year course of MEL treatment to one of a pair of monozygotic AD twins resulted in milder cognitive impairment for the treated twin [12]. Despite these epidemiologic and anecdotal reports, all of which involved low MEL doses ( $\leq 9 \mathrm{mg} /$ day), no controlled clinical studies of MEL effects on cognition in $\mathrm{AD}$ patients have been published. MEL is amphiphilic, thus it is able to penetrate all cellular compartments and freely enter the brain, especially from the CSF [13, 14]. The pharmacokinetics and oral bioavailability of exogenously-administered MEL and analogs have been well-established in preclinical and clinical studies [15].

Considerable in vitro evidence supports the premise that MEL exerts an anti-amyloid- $\beta(A \beta)$ aggregation effect [16-18]. MEL has been shown to protect against A $\beta$-induced neurotoxicity in vitro and in vivo [17-22]. We and others have also demonstrated significantly reduced amyloid plaque burden in $\mathrm{AD}$ mice treated for several months $[23,24]$. Interestingly, the neuroprotection afforded by MEL in AD mice appears to be agedependent [25] in as much as treating mice from 4 to 8 months was not found to be significantly beneficial, whereas MEL from 8 to 12 months of age (or from 4 to 12 months of age) significantly preserved cognition while reducing amyloid plaque load in these animals. In another study [26], a very low dose of MEL (0.08 $\mathrm{mg} /$ day) was administered to aged $\mathrm{Tg} 2576$ (APP ${ }^{\text {swe }}$ ) mice beginning at 14-18 months of age. Neither soluble $A \beta$ levels nor $A \beta$ deposition was affected in cortex, leading the authors to conclude that MEL is unlikely to be a treatment for already established AD. However, the low dose of
MEL utilized in their study, the very late onset of treatment, the lack of cognitive evaluation, and nonassessment of any other key markers, are clearly in contrast to our previous studies and the present study.

MEL has often been reported to have anti-inflammatory (and occasionally pro-inflammatory) properties in many species, including humans [27-29]. It is noteworthy that MEL administration lessens A $\beta$-induced proinflammatory cytokine levels in rat and mouse brains $[23,30]$. Indeed, MEL may represent a new class of anti-inflammatory agent [31], with accumulating evidence for a significant role in reducing neuroinflammation via diverse mechanisms (Hardeland et. 2015 ibid). Melatonin offers neuroprotection at the level of mitochondrial function [32,33]. Consistent with this idea, our published work points to reduced oxidative stress in a mouse model of $\mathrm{AD}\left(\mathrm{A} \beta \mathrm{PP}^{\mathrm{swe}} / \mathrm{PSEN} 1 \mathrm{dE} 9\right)$ after administration of MEL for $\geq 1$ month [23,33] and a MELmediated decrease in COX activity in the striatum of our double $\mathrm{AD}$ mice. Finally, evidence demonstrates that MEL can decrease tau hyperphosphorylation in cell cultures [34]. Another mechanism through which MEL may protect against cognitive impairment is through stabilization and enhancement of dendritic structure. Prior studies have shown that MEL is capable of preventing loss of dendritic length and number for prefrontal cortical neurons of rats subjected to global ischemia [35-37]. MEL has also been reported to promote dendritogenesis in the hippocampus [38]. Thus, MEL appears to exert multiple complementary mechanisms of action in the brain and hence may be an excellent therapeutic against AD.

Despite these consistent and significant actions of MEL on the cognition and pathology of the AD mouse brain, the mechanisms of MEL action remain unclear. In two recent reports $[39,40]$ the cognitive function of transgenic $\mathrm{AD}$ mice was assessed after treatment with the specific, nonselective MTNR ligand, Ramelteon ${ }^{\circ}$ (Takeda Pharmaceuticals), for up to 6 months. Ramelteon ${ }^{\circ}$ is a commercially available, clinically tested (for insomnia), highly specific agonist at both MTNRs, having no direct intracellular activity [41]. Intriguingly, and despite evidence for reduced hippocampal protein oxidation [40], Ramelteon ${ }^{\circ}$ in these two studies was ineffective in lowering amyloid plaque load or preserving cognitive functions. The most parsimonious interpretation of these findings is that MEL acts via MTNR-independent mechanisms to cognitively protect the amyloid-afflicted brain.

In an effort to provide clarity on this matter, we have generated transgenic A $\mathrm{PPP}^{\mathrm{swe}}$ / PSEN1dE9 (2xAD) mice that lack both known MTNRs (MTNR-) in order to determine whether MEL has neuroprotective capabilities that are independent of these receptors. Cognitive performance, $A \beta$ hippocampal plaque load, blood $A \beta_{1-40}$ 
and $A \beta_{1-42}$ levels, and key markers of brain oxidative stress were assessed in $2 x A D$ mice with or without MTNRs that received long-term MEL. Compared to NonAD mice, the 2xAD animals developed significant cognitive deficits that were lessened by MEL. In some cognitive domains this neuroprotection was seen even in the absence of MTNRs. Similarly, amyloid plaque load in the hippocampus and frontal cortex as well as circulating levels of $A \beta_{1-42}$ were significantly lowered by MEL in an MTNR-independent manner. These results strongly suggest that MEL provides neuroprotective effects in the AD brain in a manner that is to some degree independent of the two known membrane receptors.

\section{Results}

\section{Behavioral testing}

Sensorimotor and locomotor behavior

No evidence of sensorimotor deficits was seen on the Platform Recognition or Rota-rod tests at any of the ages tested (Fig. 1). There were no statistical differences between groups, trials or the interaction in the Platform Recognition test and no significant differences $(p>0.05)$ on Rota-rod performance between the two genotypes at any age. It is worth noting that these mice clearly had no visual deficits, despite their $\mathrm{C} 3 \mathrm{H}$ background, most likely because they were out crossed for multiple generations to the C57BL/6 line.

Assessment of locomotor activity was performed using the Open Field test. No statistically significant differences in the number of lines crossed per trial were seen at 12-months of age, even though 2xAD mice on the MTNR- background crossed more lines than mice with MTNRs. By 15-months of age these differences are largely attenuated as was recently described for NonAD/ MTNR-mice [42].

Anxiety behavior Determination of anxiety/emotionality was performed using the Elevated Plus Maze, which incorporates both open and closed arms, the mice generally preferring the closed arms. Thus, the greater the time spent in the open arms is considered a measure of decreased anxiety. As seen in Fig. 2, the NonAD and 2xAD mice at 12 and at 15 months of age spent similar amounts of time in the open arms, despite a clear trend

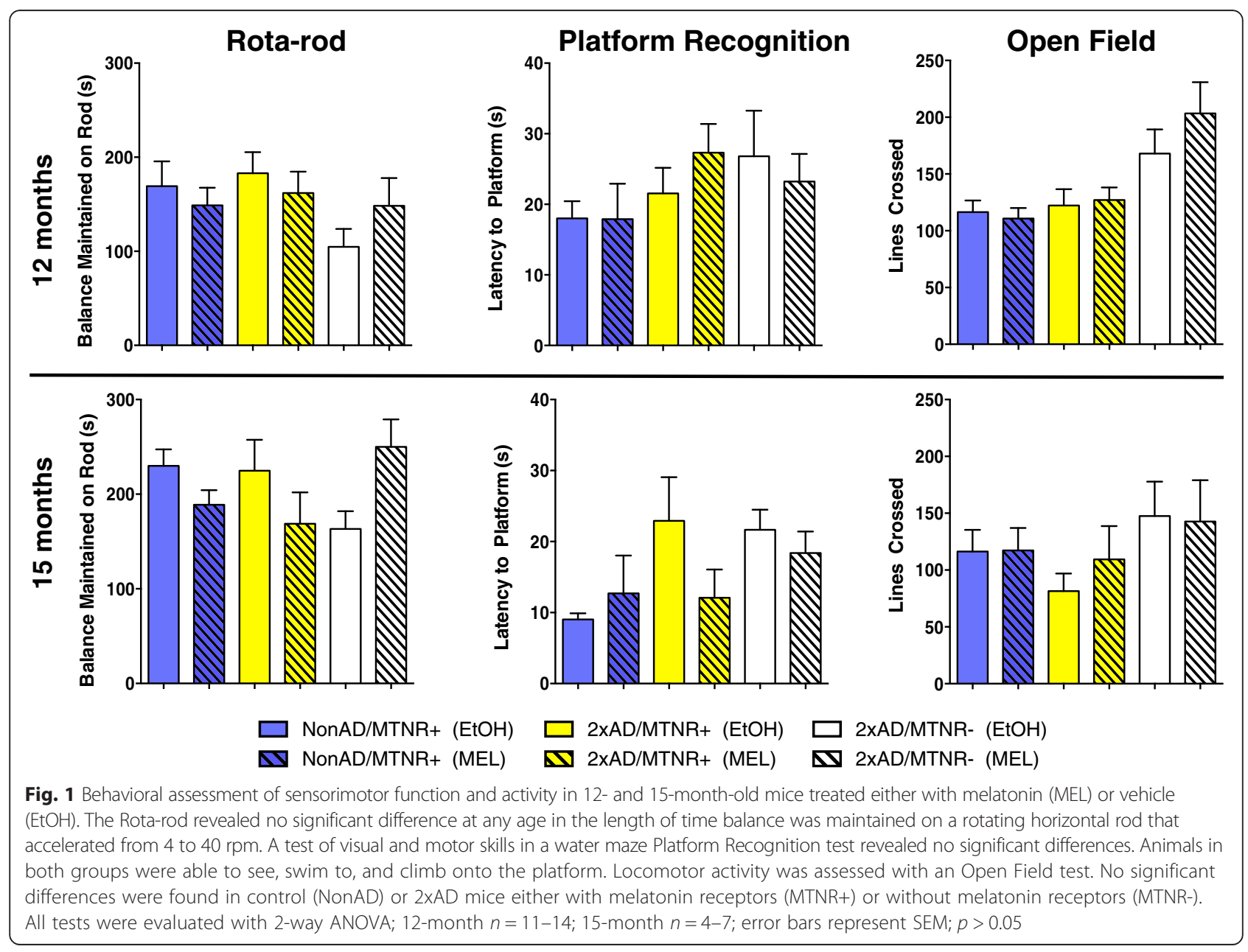



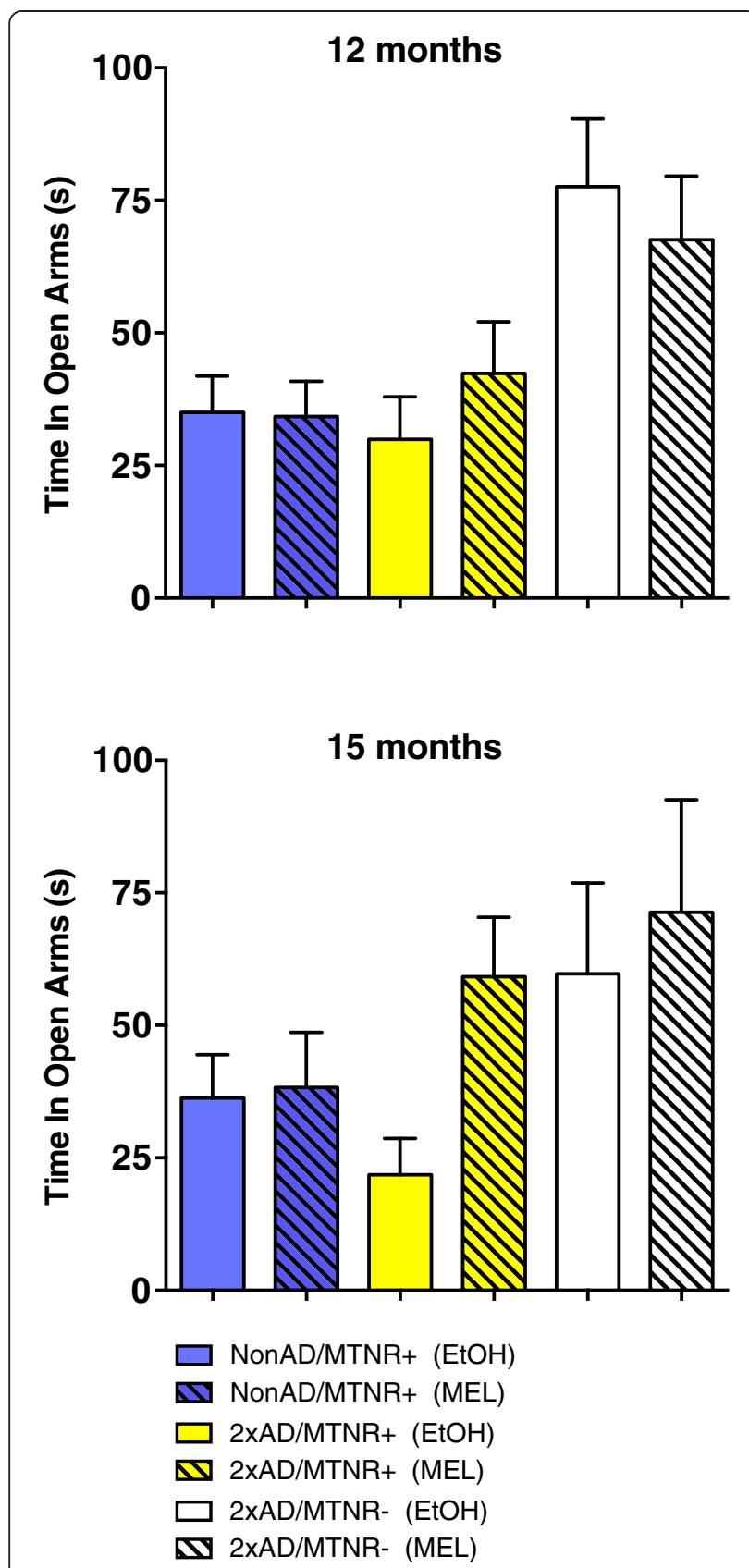

Fig. 2 Determination of anxiety levels by time in spent in the open arms of the Elevated Plus Maze. No significant differences were seen in either the 12-month-old or in the 15-month-old NonAD control or 2XAD mice, irrespective of the whether they possessed melatonin receptors (MTNR+) or lacked them (MTNR-). Evaluated with 2-way ANOVA; 12-month $n=10-13$; 15-month $n=4-7$; error bars represent SEM; $p>0.05$

to less anxiety (more time spent in the open arms) in the 2xAD/MTNR- mice at 12 months of age. Additionally, at 12 months of age, but even more apparent at 15 months, MEL tended to increase the time spent in the open arms, i.e. to reduce anxiety. However, this effect was seen only in MTNR+ mice. There were no significant group differences in the ratio of open arm entries to closed arm entries.

\section{Cognitive performance}

Non-spatial cognitive: novel object recognition test

The novel object recognition test (NORT) is a facile behavioral assay based on the spontaneous preference of rodents to interact more with an unfamiliar object than with a familiar one. As such there is little to no stress on the animal and it does not require spatial orientation. It has been used to assess deficits in learning and memory in various mouse models of $\mathrm{AD}[43,44]$. We tested the effects of MEL on performance in the NORT in 15 month-old AD mice with or without their MTNRs. As shown in Fig. 3, both groups of vehicle-treated $2 \times \mathrm{AD}$ mice performed poorly, i.e. showing almost equal times exploring the novel objects and the familiar (only small differences between the two). In contrast, the $2 \times \mathrm{AD}$ mice that were treated with MEL showed significantly improved performance levels that were comparable to the NonAD control level. These MEL effects were independent of the presence of the MTNRs. No effects of MEL were seen in NonAD mice.

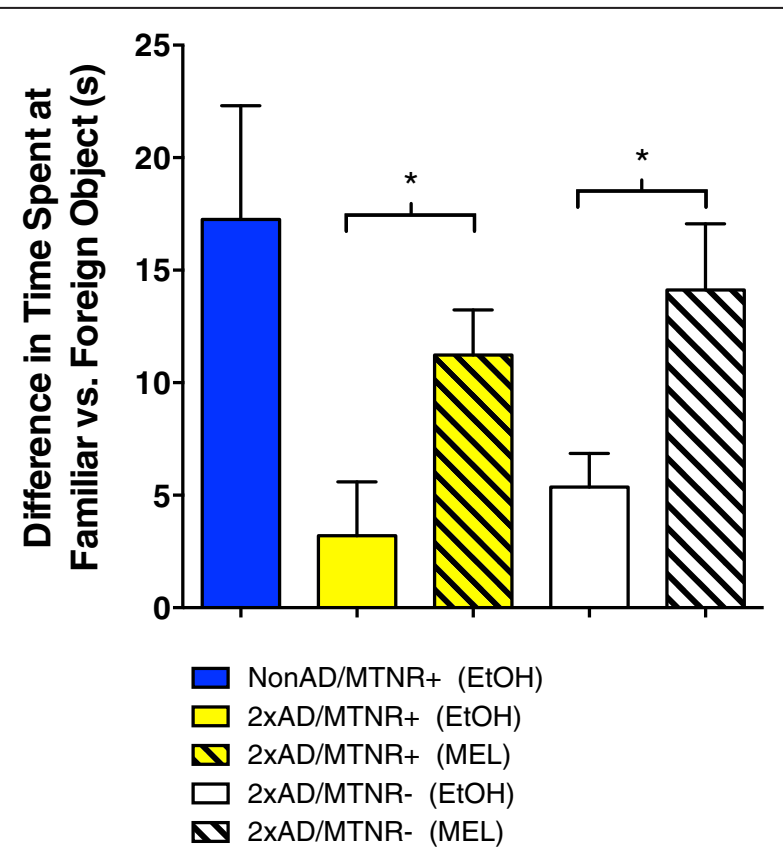

Fig. 3 Measurement of non-spatial memory in 15-month-old mice with the novel object recognition test. This test evaluates the difference in time spent investigating a familiar versus foreign object. The vehicle-treated 2xAD mice (clear yellow and white bars) showed significantly poorer performance when compared to the NonAD/MTNR+ control mice with or without MEL. This was alleviated in the $2 \times A D$ mice that had received melatonin (MEL; striped bars), irrespective of the presence (MTNR+) or absence (MTNR-) of melatonin receptors. Evaluated with 2-way ANOVA; $n=4-7$; error bars represent SEM; $p<0.05$ 


\section{Spatial cognitive: barnes maze and the morris water maze}

Mice were tested for cognitive performance with two standard behavioral tests for spatial/reference learning, the Barnes Maze (circular platform test) and the Morris Water Maze (the probe test). At 15 months of age the 2xAD/MTNR+ mice treated with MEL showed learning in the Barnes Maze by day 8 as compared to day 1 (Fig. 4a) in contrast to EtOH-treated controls. However, 2xAD/MTNR- mice were quicker in the Barnes maze in general, most likely due to their increased activity and generally improved cognition as reported previously. MEL treatment seemed to slightly potentiate this effect even in absence of the receptors.

Comparisons of the final latencies (days 5-8 of testing) to find the escape hole in the same mice at 12-month of age versus their recall at 15 -months of age (Fig. 4b)

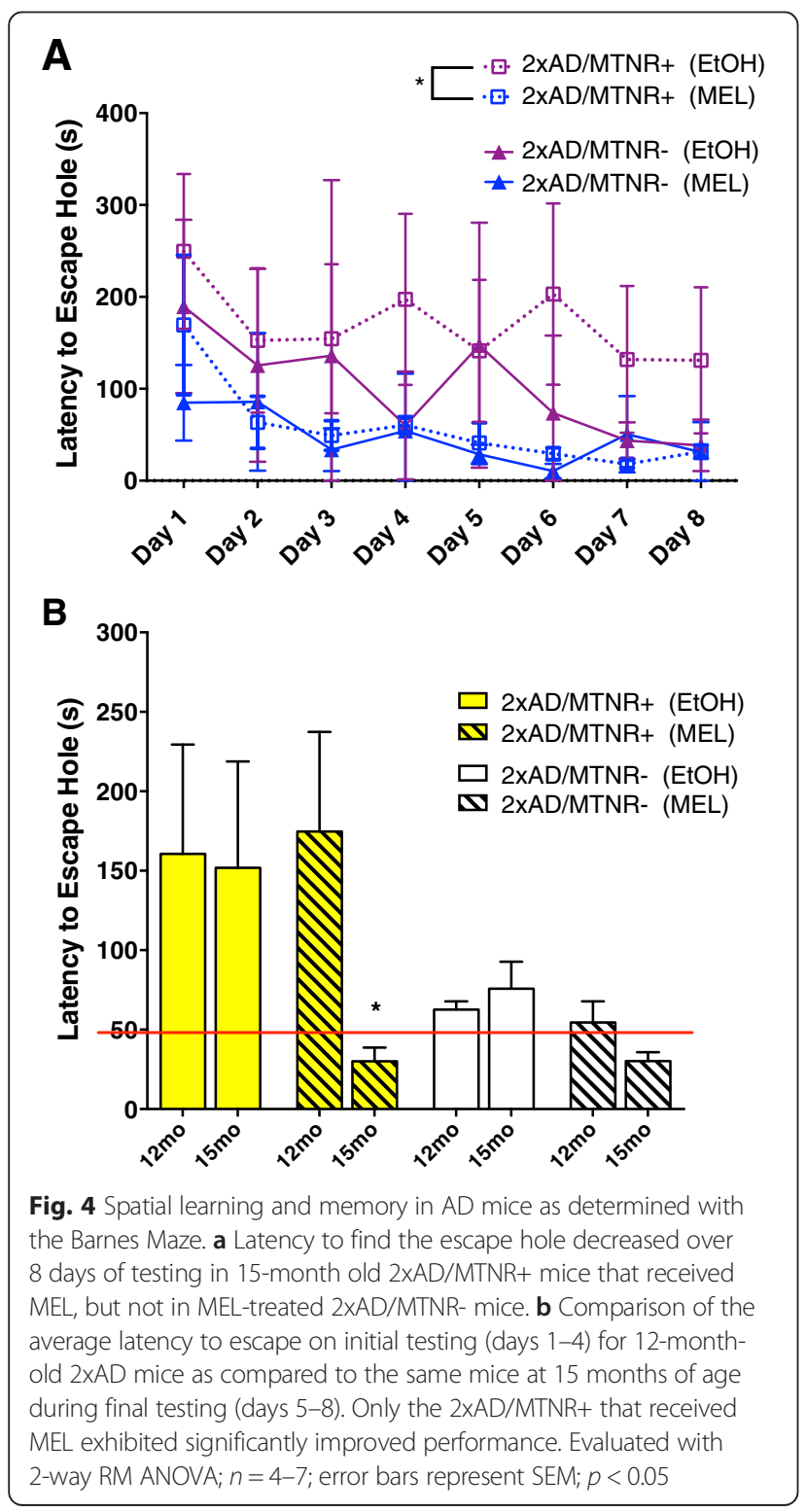

revealed that vehicle-treated mice $2 \times \mathrm{AD}$ were not able to recall and improve their performance after three months. In contrast, the MEL-treated 15-month-old $2 \times \mathrm{AD}$ mice made significant improvements over their performance at 12-months, consistent with enhanced learning capabilities. The superior performance in the $2 \times \mathrm{AD} / \mathrm{MTNR}$ - mice was likely due to the consequences of genetic deletion of the MTNRs, which gives even NonAD/MTNR- mice a cognitive advantage over MTNR+ mice as we recently reported [42]. In both 2xAD groups MEL treatment enabled superior performance at 15 months when compared to 12 months, although in the 2xAD/MTNR- group there was only marginal further improvement, presumably due to a "floor effect".

The Morris Water Maze (Fig. 5a) provides for another assessment of spatial learning (shorter escape latencies with training) as well as testing for working memory (the probe test). In the case of escape latencies, clear improvements were seen in the NonAD/MTNR+ mice when comparing the first and last training days $(\mathrm{P}<$ 0.05). Neither of the vehicle-treated 2xAD groups showed any spatial learning. However, the 2xAD/MTNR + mice that received MEL had similar rates of learning to the NonAD/MTNR+ control mice. Similar trends were seen with the probe test, where the $2 x A D$ mice spent the least amount of time in the goal quadrant (Fig. 5b) while the NonAD/MTNR+ controls spent the most time. 2xAD/MTNR+ mice that received MEL had performance levels comparable to the NonAD/MTNR+ controls.

\section{Survival curve}

In the early months of this study we noticed a significant degree of mortality in the 2xAD/MTNR- mice of our colony. A Kaplan-Meier survival plot (Fig. 6) revealed that within the first 3-9 months of age, nearly one-third of these animals were found dead in their cages, while no animals of the $2 x A D / M T N R+$ groups died. The mortality of the 2xAD/MTNR- mice was marginally, but not significantly, affected by MEL treatment. For this reason numerous cohorts of 2xAD/MTNR- mice had to be combined later in our study in order to attain sufficient animal numbers for behavioral and neuropathological studies.

\section{Immunohistochemistry}

Long-term MEL treatment induced clear reductions in amyloid beta deposition in 15-month-old 2xAD mice, as indexed by $A \beta$ burden, in both the hippocampus (Fig. 7a-d) and the frontal cortex (Fig. 7g). NonAD brains presented with essentially no plaques (Fig. 7e). Quantification of A $\beta$ plaque area (Fig. 7f,g) revealed substantial reductions of $33.5 \%$ and $18 \%$ in the brains of 


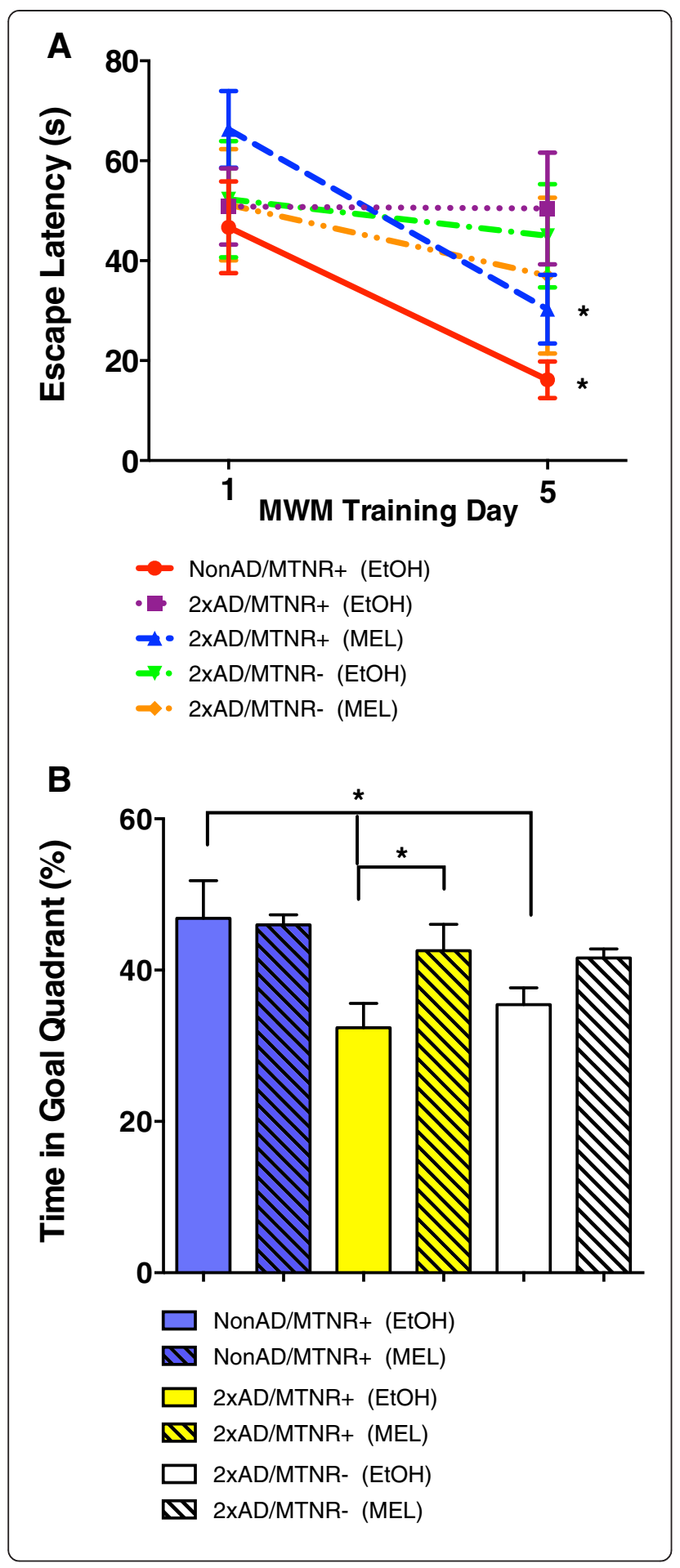

Fig. 5 Assessment of spatial learning and memory in 15-month-old mice using the Morris Water Maze. a Averaged escape latency in the Morris Water maze, training day 1 versus training day 5, with four successive trials per day. NonAD/MTNR+ vehicle treated mice (red line) showed a significant reduction in their escape latency to the submerged platform by day 5. MEL-treated 2xAD/MTNR+ mice (blue line) also had significantly improved performance while none of the other Alzheimer mice showed any significant learning. b Probe test follow-up after Morris Water maze training as determined by percentage of time spent in the goal quadrant. Retention of the memory of the goal quadrant was significantly reduced in the 2XAD mice as compared to the NonAD control mice, irrespective of the presence or absence of melatonin receptors (clear yellow and white bars). Treatment with MEL significantly improved memory in the 2XAD/MTNR+ (yellow, striped bar), but not in the 2XAD/MTNR- mice. Evaluated with 2-way RM ANOVA; $n=4-7$; error bars represent SEM; $p<0.05$

both $2 \times \mathrm{AD} / \mathrm{MTNR}+$ and $2 \times \mathrm{AD} / \mathrm{MTNR}$ - mice, respectively, that received MEL treatment.

\section{ELISA for plasma $A \beta$ peptides}

Plasma levels of the amyloid peptides $A \beta_{1-40}$ and $A \beta_{1-42}$ were determined in cohorts of $2 \mathrm{xAD}$ mice at 9 months and 14 months of age (Fig. 8). While there were no significant differences in peptide levels between 2xAD animals possessing or lacking MTNRs, there were clear trends for reduced $A \beta$ levels in the MEL-treated groups. In particular, MEL led to a significantly lowered serum $A \beta_{1-42}$ level at 14 months of age, irrespective of the presence or absence of MTNRs.

\section{Cytochrome C oxidase activity}

Melatonin receptors slightly delay the aging-induced loss of cytochrome c oxidase activity

Decreased cytochrome c oxidase (complex IV) activity is a hallmark of brain aging. Therefore, we performed

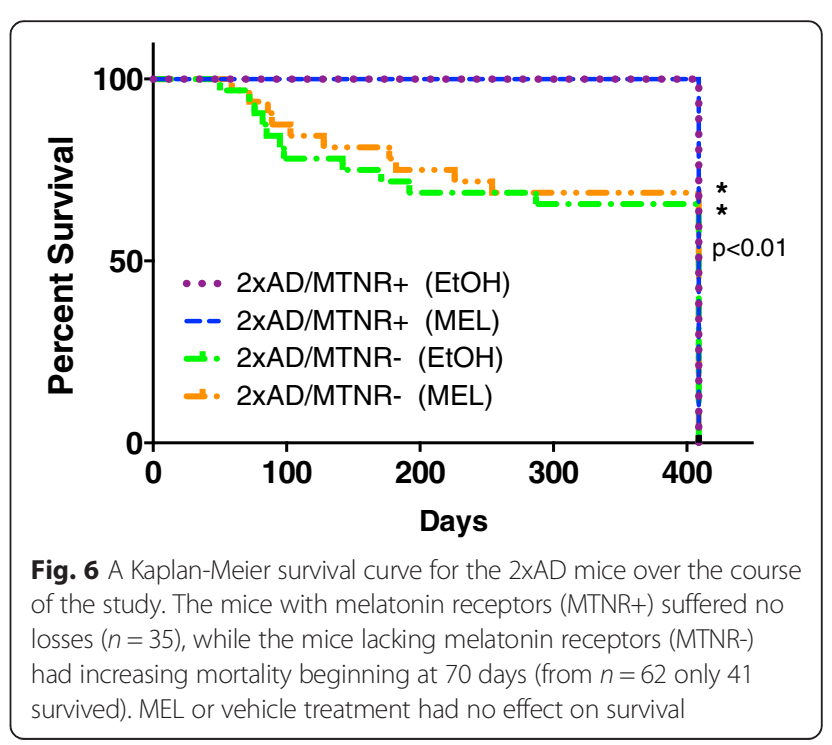




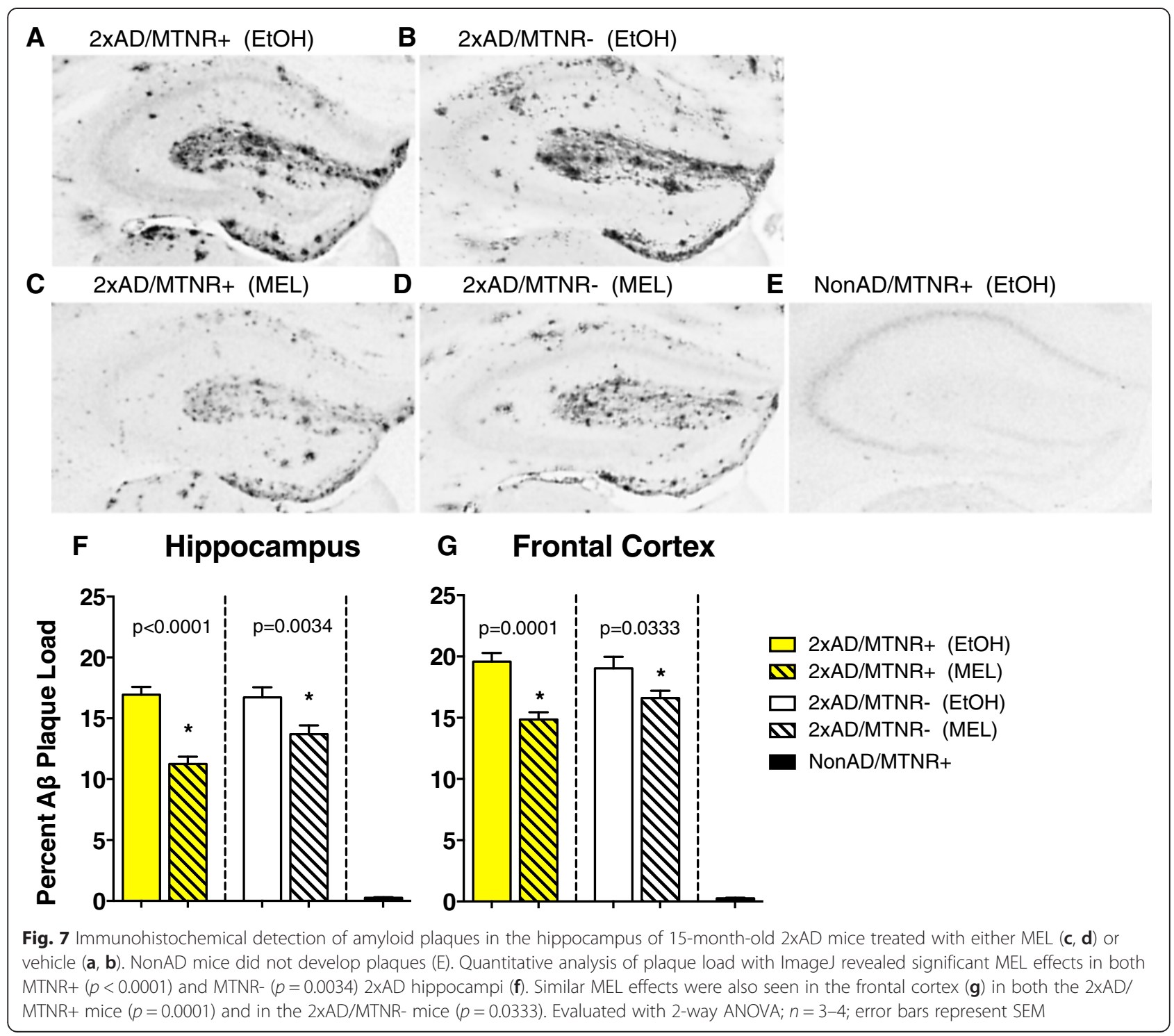

complex IV activity assays on striatal extracts on MTNR+ and MTNR- mice at 13 (Fig. 9a) and 16 months (Fig. 9b) of age. There was a striking $42 \%$ decline in COX activity during this time period in extracts from MTNR+ mice $(\mathrm{p}<0.001)$ and a $56 \%$ decline in extracts from MTNR- mice $(p<0.001)$. When MTNR- and MTNR+ mice were compared, there was a trend for decreased complex IV activity at 13 months of age $(\mathrm{p}=0.14)$ and a significant $33 \%$ reduction in complex IV activity in MTNR- mice by 16 months of age ( $\mathrm{p}=$ $0.005)$. For a reference point in young adult mice, we also measured complex IV activity at 6 months of age (data not shown). While there was no drop in complex IV activity between 6 and 13 months of age in MTNR+ mice, there was a $34 \%$ drop in complex IV activity during this time in MTNR- mice $(\mathrm{p}<0.001)$. Therefore from 6 to 16 months of age, we found that MTNR- mice showed
$33 \%$ more loss of complex IV activity than MTNR+ mice (67\% loss in MTNR- mice compared to $50 \%$ loss in MTNR+ mice). So the presence of MEL receptors slightly delays the loss of complex IV activity with normal aging.

\section{MEL-mediated prevention of the aging-induced loss of} complex IV activity is mostly independent of MEL receptors

As has been shown by others with aging [45] or hypoxia [46] in rats, we found that MEL treatment completely blocked the decline in complex IV activity from 13 to 16 months of age in both MTNR+ $(\mathrm{p}<0.001)$ and MTNR- $(p<0.001)$ mice (Fig. 9). Therefore, MEL treatment prevents the aging-related decline in complex IV activity through predominately receptor-independent mechanisms, with this being especially evident between 13 and 16 months of age. 


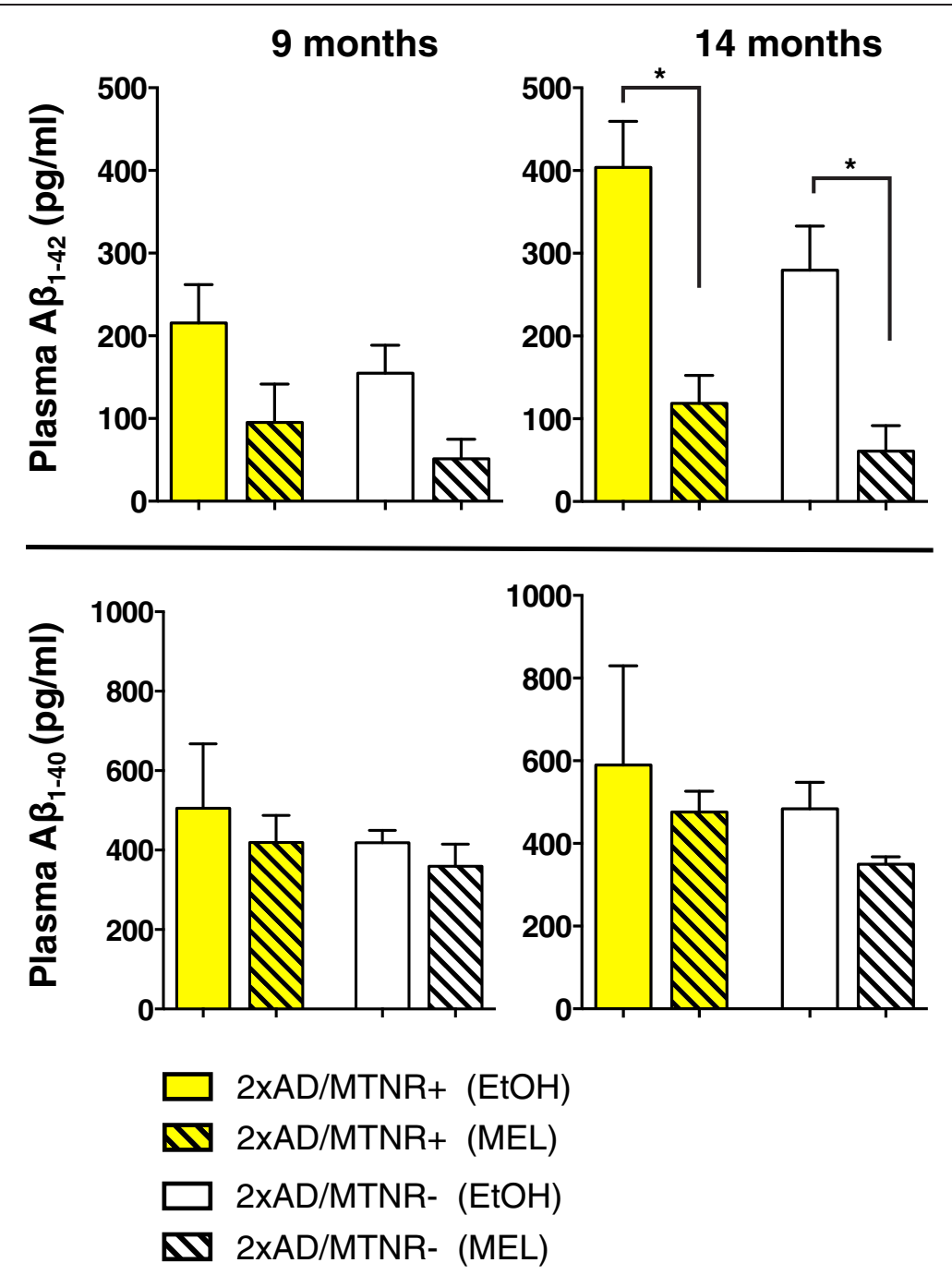

Fig. 8 ELISA measurement of plasma $A \beta_{1-40}$ and $A \beta_{1-42}$ levels in 9-month-old and 14-month-old $2 x A D$ mice. In all cases, MEL tended to lower amyloid peptide levels. A significant effect of MEL was seen at 14 months for $A \beta_{1-42}$ levels in both MTNR+ mice $(p=0.0043)$ and in MTNR- mice $(p=0.011)$. Evaluated with 2-way ANOVA; $n=3-5$; error bars represent SEM

\section{AD-induced increase in complex IV activity in 16-month mice}

Several studies have shown that $\mathrm{A} \beta \mathrm{PP}^{\mathrm{swe}}$ transgenic mice are characterized by complex IV deficiency [47, 48], as amyloid-beta has been shown to reduce complex IV activity in isolated mitochondria [49]. Unexpectedly, in our experiments (Fig. 9) there was no decrease in complex IV activity in 13-month $2 \times \mathrm{AD}$ mice when compared to NonAD and even an increase in complex IV activity from 13 to 16 months of age $(p=0.01)$. The reason for this unexpected finding is likely the hybrid vigor of the outbred strain or the examination of striatum instead of hippocampus or cerebral cortex, the brain regions most severely effected in AD. In either case, we effectively used this increased complex IV activity in the 16 month $\mathrm{AD}$ mice as a marker of an $\mathrm{AD}$-induced mitochondrial stress response when examining the effects of
MEL receptor knockout and MEL treatment. Strikingly, the unaltered complex IV activity in the $2 \times \mathrm{AD}$ mice at 13 months of age parallels the lack of behavioral and cognitive changes observed in these mice at 12 months of age. Likewise, the large changes in complex IV activity at 16 months of age correlates well with the cognitive performance decline by 15 months of age in the $2 x A D$ animals.

At 13 months of age in MTNR- mice, as with MTNR+ mice, the presence of Alzheimer's proteins did not alter complex IV activity ( $2 \times$ AD/MTNR- vs. NonAD/MTNR-). Also similar to the results observed with MTNR+ mice, a large $(45 \%)$ increase in complex IV activity from 13 to 16 months occurred when comparing NonAD/MTNR- vs. $2 \times \mathrm{AD} / \mathrm{MTNR}$ - mice ( $<0.001) .2 \times \mathrm{AD} / \mathrm{MTNR}$ - mice had roughly $26 \%$ decreased complex IV activity at both 13 months $(\mathrm{p}=0.03)$ and 16 months $(\mathrm{p}=0.02)$ of age 


\section{Cytochrome c oxidase activity}

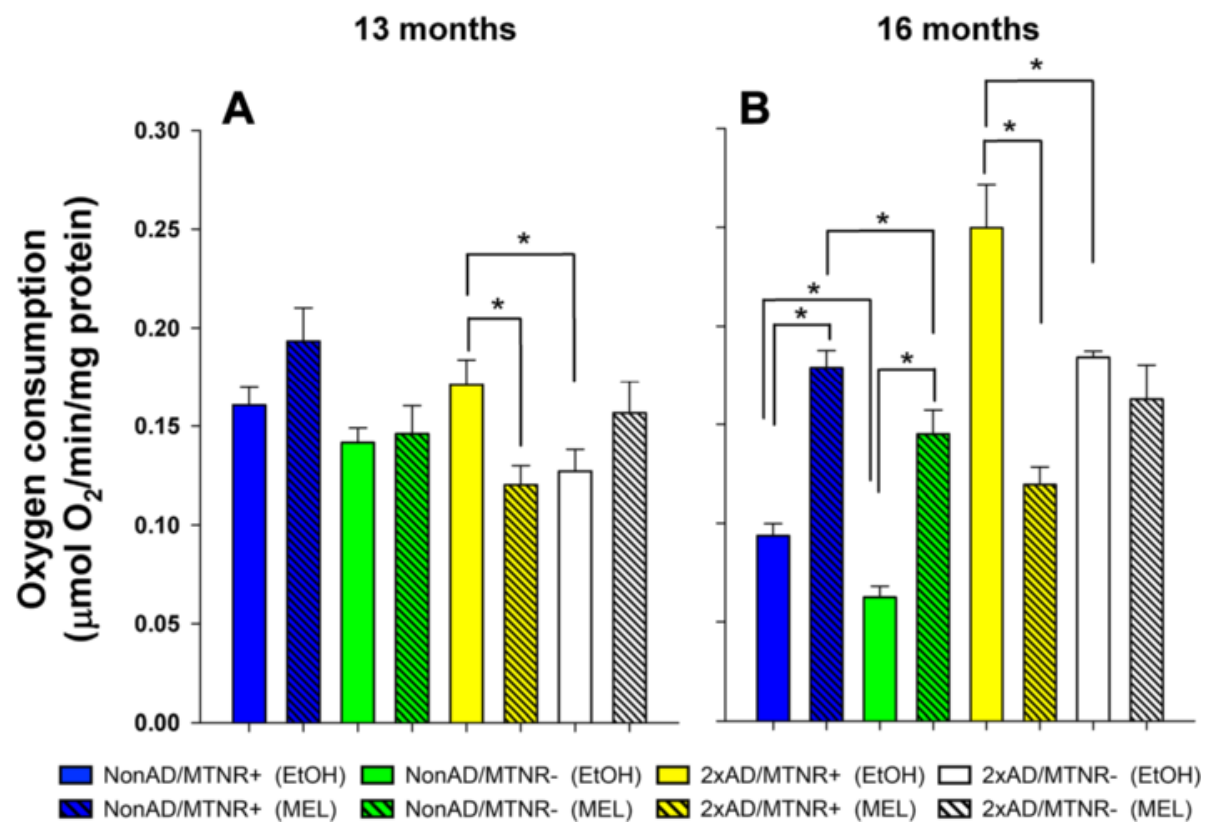

Fig. 9 Complex IV activity in striatal extracts from 13- and 16-month mice. There was a decline in complex IV activity in NonAD mice and an increase in complex IV activity in AD mice from 13 to 16 months irrespective of MEL receptor status. a At 13 months 2xAD/MTNR+ mice had higher complex IV activity than 2xAD/MTNR- mice $(p=0.03)$. MEL treatment of the 2XAD/MTNR+ mice decreased complex IV activity $\left({ }^{*} p=0.03\right)$. b At 16 months NonAD/ MTNR+ mice had higher complex IV activity than NonAD/MTNR- mice $\left({ }^{*} p=0.005\right)$ and 2xAD/MTNR+ mice had higher complex IV activity than 2xAD/ MTNR- mice $\left({ }^{*} p=0.02\right)$. MEL treated 16 month mice had higher complex IV activity in both NonAD/MTNR+ $\left({ }^{*} p<0.001\right)$ and NonAD/MTNR- ${ }^{*} p<$ $0.001)$ groups. MEL treatment prevented the increased complex IV activity in $2 x A D / M T N R+$ mice $\left.{ }^{*} p<0.001\right)$. MEL treatment of NonAD/ MTNR- mice did not restore complex IV activity to the level present in NonAD/ MTNR+ mice ( $\left.{ }^{*} p<0.05\right)$. Evaluated with 2-way ANOVA; error bars represent SEM

when compared with the aged matched $2 \times \mathrm{AD} / \mathrm{MTNR}+$ controls. However, the direction and magnitude of the change in the complex IV activity due to Alzheimer's protein expression were similar in the $2 \times \mathrm{AD} / \mathrm{MTNR}$ - and 2xAD/MTNR+ mice.

\section{Melatonin treatment reduces the high complex IV activity in 2XAD/MTNR+ mice}

Surprisingly, MEL treatment greatly decreased complex IV activity in the $2 \times \mathrm{AD} / \mathrm{MTNR}+$ mice, $30 \%$ at 13 months $(\mathrm{p}=0.03)$ and $52 \%$ at 16 months $(\mathrm{p}<0.001)$. This is the only group where MEL treatment decreased complex IV activity (Fig. 9). This MEL-mediated decrease in complex IV activity in the $2 \times \mathrm{AD}$ mice is consistent with a mechanism in which there is a reactive oxygen species (ROS)-mediated increase in complex IV activity in $2 \times \mathrm{AD}$ mice that is prevented by melatonin treatment. In the $2 \times \mathrm{AD} /$ MTNR- mice, the complex IV activity was lower than in $2 \mathrm{xAD} / \mathrm{MTNR}+$ mice and melatonin treatment did not have a statistically significant effect on the activity.

\section{Antioxidant transcript analysis by $\mathrm{qPCR}$}

For tissues collected at 13 months, expression levels of superoxide dismutase 1 (SOD1), glutathione peroxidase
1 (GPx-1), and catalase (CAT) were determined in the frontal cortex by quantitative PCR. Additionally, we measured the transcript levels of nuclear factor erythroid 2-related factor 2 (Nrf2), a transcription activator that binds to antioxidant response elements in many genes involved in the cellular response to oxidative stress. Figure 10 shows that in both NonAD and 2xAD mice, the very marked effects of MEL versus vehicle $(0.1 \%$ ethanol) on antioxidant signaling in MTNR+ mice are notably absent in MTNR- mice.

\section{Discussion}

Transgenic mice models for studying the cellular and molecular basis of AD have been used for many years, but rarely for investigations into the therapeutic potential of MEL to slow the progression of this disease [24, 50, 51]. Our 2009 publication [23], detailed the neuroprotective effects of long-term oral MEL administration ( $\sim 0.5 \mathrm{mg} /$ day) on cognitive performance, brain $\mathrm{A} \beta$ levels/deposition, and antioxidant enzyme expression in the $\mathrm{A} \beta \mathrm{PP}^{\mathrm{swe}} / \mathrm{PSEN} 1 \mathrm{dE}$ ( $2 \mathrm{xAD}$ ) mouse model. Subsequent recent studies continue to demonstrate that MEL has significant and reproducible prophylactic properties in several mouse models of $\mathrm{AD}[33,52,53]$. 


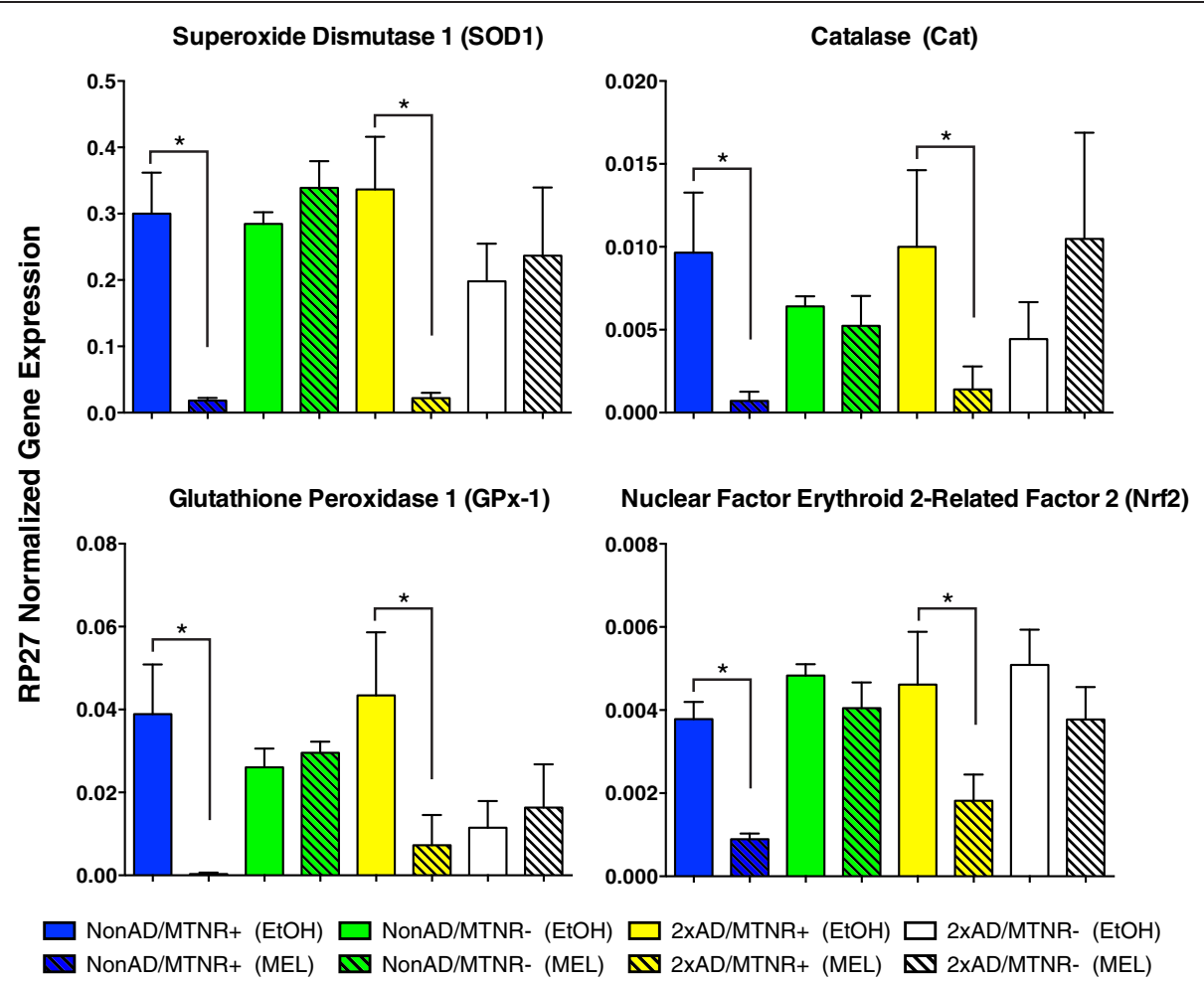

Fig. 10 Melatonin treatment effect on anti-oxidant transcript expression in frontal cortex of 13-month old mice. Melatonin significantly $(p<0.05)$ lowered transcript levels for four markers of the antioxidant response system in a receptor-mediated fashion. This effect was seen in both NonAD and 2XAD mice that possessed melatonin receptors (MTNR+), but not in mice that lacked these (MTNR-). Evaluated with 2-way ANOVA; $n=4-6$; error bars represent SEM

The primary goal of the present study was to determine the role of the cognate G-protein coupled melatonin receptors in mediating the neuroprotective action of MEL in the 2XAD mouse model. As reported by the supplier (Jackson Laboratories) the 2xAD animals begin developing cognitive deficits after 12 months [54]. We saw no significant cognitive deficits at 12 months of age when using three common behavioral tests (data not shown). However, at 15 months the picture was markedly different. Using the novel object recognition test (NORT), which assesses short-term memory in a nonspatial task, the cognitive protection afforded the $\mathrm{AD}$ mouse brain by MEL was equivalent in both the mice with MTRs as well as in the KO mice lacking MTNRs (Fig. 3). Whereas both vehicle-treated AD groups performed poorly (i.e. they were unable to recognize novelty), the MEL-treated 2xAD mice were able to perform at the level of the non-transgenic (NonAD) vehicletreated control mice irrespective of whether they were with or without the melatonin receptors. These results are consistent with the view that MEL preserves nonspatial cognitive performance in $2 \times \mathrm{AD}$ mice even in the absence of G-protein coupled membrane MTNRs.

Additional cognitive testing was conducted with the circular platform (Barnes) test for spatial reference learning and memory (Fig. 4). In this test, 15 month-old 2xAD mice without melatonin receptors that had received MEL had lower latencies to the escape hole on day 1 , while the $2 \mathrm{xAD}$ mice with receptors learned to be even faster over the course of the 8-day testing paradigm when compared to vehicle-treated controls (Fig. 4a). The day 1 differences likely reflect enhanced long-term memory in MEL-treated mice, as the same animals were tested earlier at 12 months of age. Fig. $4 \mathrm{~b}$ depicts comparative performance on the Barnes test between 12 months and 15 months of age. Significant improvements with age were seen in the $2 \times \mathrm{AD}$ mice that had received MEL, with more pronounced improvements in the MTNR+ mice.

Mice were also tested with the Morris Water Maze, which includes elements of spatial learning as well as assessment of working memory. As would be expected, the NonAD/MTNR+ mice performed well in both domains (Fig. 5), while the vehicle-treated $2 \times \mathrm{AD}$ groups performed poorly on both. Notably, cognitive performance of the 2xAD/MTNR+ mice that received MEL was similar to the NonAD/MTNR+ control mice for both testing components. $2 \times \mathrm{AD} / \mathrm{MTNR}$ - mice that received MEL did not show neuroprotection, as their performance levels were comparable to the vehicle-treated 
$2 \times A D / M T N R-$ mice. Thus, the results of these cognitive tests confirm that MEL is capable of preserving memory in $2 \times \mathrm{AD}$ mice in both non-spatial and spatial domains, as shown previously by several research groups $[23,25,40]$. Additionally, our new data reveal that MEL effects are dependent on the MTNRs in the case of hippocampaldependent spatial learning tasks, such as the Barnes Maze and the Morris Water Maze, but independent of MTNRs for non-spatial learning.

Acute MEL administration has been reported to have anxiolytic effects in both animal models $[55,56]$ and in human trials $[57,58]$. In addition, Ochoa-Sanchez and colleagues [59] reported that the novel MT2- selective agonist, UCM765, showed anxiolytic properties in the Open Field test and Elevated Plus Maze. Recently, Di Paolo et al. [60] reported that MEL had anxiolytic effects in both NonAD and $\operatorname{Tg} 2576\left(\mathrm{~A} \beta \mathrm{PP}^{\mathrm{swe}}\right)$ mice. In the present study, we could confirm that the anxiolytic effects of MEL depended on the presence of the MTNRs (Fig. 2). MEL trended to influence anxiety in the 2xAD mice, but only in the presence of melatonin receptors.

For the sake of completeness we also assessed sensorimotor function at 12 and 15 months of age in 2xAD and control mice receiving MEL. No evidence of sensorimotor deficits was seen on the Rota-rod or Platform Recognition tests at any of the ages tested (Fig. 1) and there were no statistical differences between any genotypes or treatment groups. The slight improvements in both tests at 15 months vs. 12 months are likely to be due to the effects of experience. Furthermore, despite their $\mathrm{C} 3 \mathrm{H}$ background, these mice clearly had no visual deficits, as was confirmed by the behavioral performance on various tests requiring spatial learning (see Figs. 4 and 5). Evaluation of open field activity at 12 months and at 15 months of age revealed no significant differences in any groups (Fig. 1). The slightly increased activity levels seen in the 2xAD/MTNR- mice at 12 months is likely a consequence of genetic deletion of the MTNRs, which we have recently demonstrated to be associated with mild hyperactivity [42].

As a neuropathological correlate of AD progression in these animals we assessed amyloid plaque load by immunohistochemistry in the hippocampi and frontal cortex of 15 month-old mice. A significant reduction of plaque area was seen in MEL-treated mice as compared to vehicle (Fig. 7), with MTNR+ mice that received MEL having $33.5 \%$ less plaques than controls $(\mathrm{P}<0.001)$, while MTNR- mice that received MEL having $18 \%$ less plaques than controls $(\mathrm{P}=0.0034)$, thus comprising the majority of the protective effect of the MEL treatment on plaque deposition. Identical plaque loads were seen in control $2 x \mathrm{AD}$ mice, indicating that the genetic deletion of the melatonin receptors does not predispose the animals to more severe neuropathology as they age.
Indeed, in our recent comprehensive characterization of the NonAD mice [42] we demonstrated that the MTNRgenotype slightly, but significantly, did just the opposite, i.e. it enhanced motor performance, cognitive function and long-term potentiation as measured in a hippocampal slice preparation. The plaque results from the current study (Fig. 7) confirm that the neuroprotective effects of MEL are largely independent of melatonin receptors, although maximal protection was achieved when melatonin receptors are expressed. In other words, both receptor signaling pathways as well as direct intracellular effects of MEL appear to contribute to its plaque-inhibiting mechanism of action with direct, receptor-independent actions predominating.

Although not the central focus of the current investigation, it is perhaps worthy to note that the $2 \times \mathrm{AD}$ mouse model has been described by the commercial supplier as having a significant degree of mortality due to seizures in early life [61]. While we saw no evidence of seizures for the mice expressing the melatonin receptors, we did notice that the $2 \times \mathrm{AD}$ mice without melatonin receptors succumbed in significant numbers in the first 6-9 months of life (Fig. 6). Brains from these animals showed no signs of plaque formation at 4 months and furthermore, at the completion of the study cognition in these animals with melatonin treatment was similarly protected as in the $2 \mathrm{xAD} / \mathrm{MTNR}+$ mice (Figs. 4 and 5). Administration of MEL to this group only marginally slowed the loss of the 2xAD/MTNR- mice. It is not entirely clear why the genetic deletion of the melatonin receptors is associated with poor early survival in the $2 \times \mathrm{AD}$ mice, although an alteration in the balance between inhibitory and excitatory circuits in mice lacking the melatonin receptors [42] might be a possibility worth further testing.

The processing of the amyloid precursor protein in the $\mathrm{AD}$ brain generates the pathogenic peptides, $A \beta_{1-40}$ and $A \beta_{1-42}$, with the latter thought to be the major neurotoxic species [62,63]. Although the blood amyloid levels in this mouse model of AD reflect both central and peripheral APP processing and clearance, we felt that as an indirect measure of MEL's potential to alter these activities, it would be informative to assess plasma levels of these peptides in our 2xAD mice during the course of plaque development. Thus, using commercial ELISAs we determined plasma levels of $A \beta_{1-40}$ and $A \beta_{1-42}$ at ages 9 (cognitively presymptomatic) and 14 months (Fig. 8). At 9 months of age - when plaques are beginning to accumulate - treatment of 2xAD mice with MEL led to lower plasma levels of $A \beta_{1-40}$ and $A \beta_{1-42}$ in the MTNR+ mice and a similar trend in the MTNR- mice. By 14 months of age (by which time cognitive symptoms are fully expressed), MEL-treated 2xAD mice of the MTNR+ genotype had a significant reduction in plasma $A \beta_{1-42}$ as well 
as the $A \beta_{1-42} / A \beta_{1-40}$ ratio (data not shown), concomitant with significantly lower amyloid load in the brain (Fig. 7). In view of evidence that $A \beta_{1-40}$ and $A \beta_{1-42}$ may be cleared from the brain by different mechanisms $[64,65]$, our overall results are consistent with a general reduction of amyloidogenic APP processing (rather than $A \beta$ clearance) in response to MEL administration. In agreement with this hypothesis [25] measured hippocampal levels of $A \beta_{1-40}$ and $A \beta_{1-42}$ in the Tg2576 AD mouse and reported significant reductions following treatment with MEL. Additionally, this group demonstrated that MEL treatment decreases $A \beta$ processing via reductions of hippocampal presenilin and $\beta$-secretase levels. More recently, Shukla et al. 2015 reported that MEL upregulates alpha-secretase protein levels and subsequent catalytic cleavage of betaAPP to nonamyloidogenic products in cultured neuronal and non-neuronal cells [66]. Thus, our current results showing melatonin receptor-independent MEL-induced decreases in plasma $A \beta_{1-42}$ levels (Fig. 8), concomitant with protection of non-spatial cognitive performance (Fig. 3) and reduced amyloid plaque load following MEL (Fig. 7) are consistent with the hypothesis that MEL's neuroprotective activities are at least in part due to its longterm effects on $\mathrm{A} \beta$ generation.

Brain mitochondrial function, which is very sensitive to oxidative stress and is impaired in $\mathrm{AD}$ [67-69], is protected by MEL through numerous mechanisms. For example, we reported recently that chronic MEL treatment protected in a dose-dependent manner against $A \beta$ mediated mitochondrial dysfunction at multiple levels in 2xAD mice and that this protection could be blocked by use of specific melatonin receptor antagonists [33]. As a further exploration of this phenomenon, we assessed the brain activity of the mitochondrial enzyme, cytochrome c oxidase (complex IV), in 2xAD mice possessing or lacking MTNRs. Striatal samples were assessed, as all of the hippocampal and cortical tissues from these animals were used for other purposes. However, in our previous study [47] we found that mitochondrial respiratory activity in all three of these brain regions of 2xAD mice were similar.

Unexpectedly, we found increased complex IV activity caused by $\mathrm{A} \beta \mathrm{PP}^{\text {swe }} / \mathrm{PS} 1$ expression from 13 to 16 months of age, not decreased expression as we and others have observed when studying $\mathrm{A} \beta \mathrm{PP}^{\text {swe }}$ Alzheimer's mice of different genetic backgrounds [33, 70]. We have confidence in our complex IV activity measurements in this report as it is well established that there is an agingrelated decline in complex IV activity in rodent brain [71]. This increased complex IV activity in 16-month 2xAD mouse brain may be mediated by mitochondrial proliferation or increased expression of oxidative phosphorylation complex subunits in response to oxidative stress $[72,73]$. If the oxidative stress is mild or of short duration, mitochondrial proliferation or increased expression of oxidative phosphorylation complex subunits may increase energy reserves to maintain cellular homeostasis, but when the oxidative stress is high or chronic such as in AD, mitochondria become damaged and these compensatory mechanisms become ineffective in restoring energy levels leading to cell and tissue dysfunction. The hypothesis that the increased complex IV activity in the 2xAD mice is caused by oxidative stress is supported by the observation that MEL treatment of the 2xAD/MTNR+ mice completely prevented the increased complex IV activity. MEL likely accomplishes this by both directly scavenging ROS and by decreasing the production of ROS from the electron transport chain [74]. Melatonin can reduce electron leakage from complexes I and III of the ETC. This can importantly lead to reduced formation of nitric oxide [75], peroxynitrite, and peroxynitrite-derived free radicals such as hydroxyl radicals and nitrogen dioxide, which prevent increased $\mathrm{NADPH}$ oxidase and iNOS activities, with an overall effect of decreasing neural inflammation [29].

Consistent with our current findings of increased complex IV activity in the $2 \times \mathrm{AD}$ mice, another group also found increased complex IV activity in A $\beta P P$-expressing mice [76]. They found increased COX activity in the ventral striatum of A $\mathrm{PP} 23$ mice partially backcrossed onto a C57BL/6 background. This report showed increased complex IV activity only in specific regions of the brain. In another report, complex IV activity increased in $\operatorname{Tg} 2576$ mice at 5 months of age compared to controls [77]. Another group found similar results with these mice at 7 months of age [78]. Consistent with both of these reports, $\operatorname{Tg} 2576$ mice show upregulation of mitochondrial electron transport genes [79]. Increased complex IV activity has also been found in neurons from Alzheimer's patients [80]. This increased electron transport chain complex activity is consistent with the Inverse Warburg Hypothesis of Alzheimer's disease, which states that aged, energetically stressed neurons attempt to upregulate oxidative phosphorylation to use the lactate produced by adjacent astrocytes as a respiratory substrate to maintain cellular ATP levels [81]. However, several other groups have measured decreased complex IV activity in various brain regions of $\operatorname{Tg} 2576$ mice [70, 8284]. In addition, reduced complex IV activity has also been measured in double and triple transgenic mouse models of $\mathrm{AD}$ combining overexpression of presenilin-1 and/or tau with mutant APP overexpression $[85,86]$.

A recent report has shown that the $A \beta$ peptide directly inhibits complex I activity of the ETC. [87]. The inhibition of complex IV activity was found to be an indirect result from damage of the mitochondrial phospholipid cardiolipin, required for complex IV activity. Cardiolipin was found to be oxidized as a result of the complex I 
inhibition, and not from a direct inhibition of complex IV by $A \beta$ as has previously been suggested [49]. Cardiolipin peroxidation is most frequently catalyzed by the cardiolipin peroxidase activity of a cytochrome ccardiolipin complex [88]. Adding back cardiolipin to aged mitochondria has been shown to restore complex IV activity [43]. In addition, $A \beta$ has been shown to decrease transcription of specific complex IV subunits in certain cell types that may also contribute to the decreased complex IV activity [89]. In the 2xAD mice used in this report, altered electron transport chain function in response to increased amyloid-beta levels may have led to decreased activity of the cardiolipin peroxidase activity of cytochrome c, preserving or even increasing cardiolipin levels resulting in the increased complex IV activity measured.

Another possible reason as to why we were able to measure increased complex IV activity in the 2xAD mice is because we used brain extracts where increased mitochondrial proliferation can be detected, in contrast to when measurements are made using isolated mitochondria where increased mitochondrial proliferation is likely missed unless paying close attention to the mass of mitochondria isolated. It is also possible that complex IV activity was upregulated in the 2xAD brain without increases in mitochondrial proliferation. This could be accomplished through expression of alternative complex IV subunits [90] or through post-translational modification of the complex [91]. When damaged cardiolipin limits complex IV activity slowing the rate of electron transport, oxygen has more time to bind the electrons producing superoxide. Under these conditions increasing complex IV activity would be an effective strategy to increase the rate of electron transport to increase ATP levels while also decreasing mitochondrial superoxide production. In summary, our data show that MEL administration protects MTNR+ mice from AD-induced upregulation of complex IV activity. However, MEL administration did not completely restore the increased complex IV activity in the 2xAD/MTNR- mice suggesting both receptor-dependent and independent effects are important for protection. It is of interest to perform similar experiments using additional brain regions and a different genetic background of mice to determine if these restorative effects of MEL are observed when complex IV activity declines as a result of $\mathrm{APP}_{\text {swe }}$ expression.

Substantial data have accumulated that link oxidative stress to AD pathogenesis [92-94]. It is thus significant to note that numerous studies have reported MEL effects on markers of oxidative stress [95-98]. Acutely, MEL has been reported to elevate in many tissues the expression of antioxidant enzymes as part of a defense mechanism against free radicals [14, 99]. Previously, we have shown significant effects of long-term MEL on
SOD1, GPx-1, and CAT mRNA expression in the brain of 10-month-old 2xAD/MTNR+ mice [23]. Also, in the present study, we evaluated antioxidant expression at 13 months of age. As seen in Fig. 10, long-term MEL treatment was associated with lower mRNA expression of Nrf2, SOD1, GPx-1 and CAT in the brain (frontal cortex) of 13 month-old mice in both 2xAD and agematched NonAD mice. A lower expression of antioxidant mechanisms is the logical outcome for brains that have reduced levels of oxidative stress due to chronic MEL treatment. These results are entirely consistent with our previous study [33] demonstrating MTNRdependent effects of MEL in the 2xAD brain. Thus, in view of our current data demonstrating that the effects of MEL on some cognitive functions and on amyloid pathogenesis in 2xAD mice are independent of MTNRs (Figs. 3, 7, and 8), the clear implication of our current study is that the potent effect of MEL on antioxidant gene expression in the 2xAD brain is not the key mechanism for its remarkable neuroprotective capabilities.

\section{Conclusions}

Melatonin has been shown to have reproducible and significant protective properties in a variety of neurodegenerative diseases. While often assumed to involve receptor signaling through one or both of the MTNRs, a direct test of this assumption with animals completely lacking their MTNRs has never been reported. In the current study with $2 \times \mathrm{AD}$ mice we have demonstrated that in some cognitive domains (spatial learning and memory) MEL neuroprotection is indeed receptordependent, while in others (non-spatial learning and memory) it is receptor-independent. In addition, hippocampal and frontal cortical amyloid plaque loads and plasma $A \beta_{1-42}$ levels were significantly reduced by MEL in a receptor-independent manner, while MEL reduced cortical antioxidant gene expression in a receptordependent manner. These findings demonstrate that long term MEL significantly reduces AD neuropathology and some associated cognitive deficits in a manner that is independent of antioxidant pathways. Future identification of direct molecular targets for MEL action in the brain should open new vistas for the development of future AD therapeutics.

\section{Materials and methods \\ Animals}

All mice were housed and handled in accordance with Federal animal welfare guidelines and in compliance with the Public Health Service Policy on Humane Care and Use of Laboratory Animals (2002) and the Guide for the Care and Use of Laboratory Animals ( $8^{\text {th }}$ Edition). Experiments were reviewed and approved prior to being carried out by the Institutional Animal Use and Care 
Committee (IACUC) of the Florida State University (Protocols \#1016, 1135; Association for Assessment and Accreditation of Laboratory Animal Care International accreditation unit \#001031; Office of Laboratory Animal Welfare Assurance \#A3854-01).

The AD double mutant transgenic mice with a C57BL/6 x C3H background were obtained from the Jackson Laboratory (stock \# 004462), into which two mutant transgenes were inserted at a single locus. One transgene encodes a chimeric human/murine amyloid beta (A4) precursor protein $\left(\mathrm{A} \beta \mathrm{PP}^{\mathrm{swe}}\right)$, which was then further modified to encode the Swedish mutations K595N/M596L found in human. The other transgene encodes the "DeltaE9" mutation of human presenilin 1 which is a deletion of exon 9 and corresponds to a form of early-onset Alzheimer's disease. The $\mathrm{A} \beta \mathrm{PP}^{\mathrm{swe}} / \mathrm{PS} 1$ transgenic mouse model (2xAD) was maintained in a hemizygous colony.

We also used a progeny of a University of Massachusetts Medical School mouse colony, where the melatonin receptor knockout strains were generated by a genetic mutation introduced by homologous recombination $[100,101]$. Briefly, sites within exon 1 of both the melatonin type 1 receptor gene $\left(\mathrm{MT}_{1}\right)$ and the melatonin type 2 receptor gene $\left(\mathrm{MT}_{2}\right)$ were replaced with phosphoglycerate kinase promoter (PGK-neomycin) cassettes. These C57BL/6 animals were then backcrossed for 10 generations to $\mathrm{C} 3 \mathrm{H} / \mathrm{He}$ mice because others have used the $\mathrm{C} 3 \mathrm{H}$ strain extensively in examining circadian behavioral responses to melatonin, as the $\mathrm{C} 3 \mathrm{H}$ strain has rhythmic melatonin production [102] unlike most other inbred strains of mice, including the C57BL/6 [103, 104]. The resultant mice were $\mathrm{C} 3 \mathrm{~B} 6(\mathrm{C} 3 \mathrm{H} / \mathrm{He}+\mathrm{C} 57 \mathrm{BL} / 6)$ melatonin receptor homozygous double knockout mice $\left(\mathrm{MT}_{1}^{-1-} / \mathrm{MT}_{2}^{-1-}\right)$, referred to here as MTNR- mice, and their non-transgenic wild-type counterparts, referred to here as MTNR+ mice.

The $\mathrm{A} \beta \mathrm{PP}^{\mathrm{swe}} / \mathrm{PS} 1$ heterozygous mice were outcrossed to the melatonin receptor double knockout mice or their non-transgenic, wild-type counterparts to obtain mice that that either had or did not have the $\mathrm{A} \beta \mathrm{PP}^{\mathrm{swe}} / \mathrm{PS} 1$ mutations and had or did not have their melatonin receptors. Henceforth, we use the following nomenclature: 2xAD mice without their melatonin receptors are referred to as $2 \mathrm{xAD} / \mathrm{MTNR}$ - and the $2 \mathrm{xAD}$ mice possessing their two melatonin surface receptors are termed $2 \mathrm{xAD} / \mathrm{MTNR}+$. The mice without the A $\beta \mathrm{PP}^{\mathrm{swe}} / \mathrm{PS} 1 \mathrm{mu}-$ tations are termed "NonAD" and therefore, have the following designations: NonAD/MTNR- for the mice without the $\mathrm{AD}$ mutations and without their melatonin receptors, but NonAD/MTNR+ for mice without the $\mathrm{AD}$ mutations, but possessing their melatonin receptors. This last group is the complete wild-type, non-transgenic control group. We then administered either melatonin
(100 $\mu \mathrm{g} / \mathrm{ml} ; ~ 0.5 \mathrm{mg} / \mathrm{day} ;$ Sigma M5250) or vehicle (0.1\% ethyl alcohol; EtOH; Electron Microscopy Sciences 15058) in the drinking water to mice beginning at 4 months of age. On the basis of a human equivalency conversion [105] our $0.5 \mathrm{mg}$ daily dose per mouse corresponds to a daily human dose of $150 \mathrm{mg}$ (for a $75 \mathrm{~kg}$ individual). Melatonin stocks were made fresh weekly in $\mathrm{EtOH}$ at $100 \mathrm{mg} / \mathrm{ml}$, then diluted 1:1000 in distilled water. The water bottles were darkened to prevent the melatonin from enhanced degradation due to light exposure. Multiple cohorts of the four genotypes were treated and behaviorally tested at 12 or 15 months of age and then sacrificed for tissue collection.

The animals were housed individually in a polycarbonate cage (Ancare; $19 \mathrm{~cm} \mathrm{x} 29 \mathrm{~cm} \mathrm{x} 13 \mathrm{~cm}$ ) with hardwood laboratory bedding chips (Nepco Beta Chip ${ }^{\oplus}$ ), nesting material (Ancare Nestlet), and a polycarbonate mouse igloo (Bio-Serv) for enrichment. They were maintained under a $12 \mathrm{~h}$ light-dark cycle (7 am to $7 \mathrm{pm}$ ) at $21.1{ }^{\circ} \mathrm{C}$ and given ad libitum access to LabDiet ${ }^{\oplus} 5001$ Rodent Chow and water.

\section{Genotyping by PCR}

At approximately 21 days of age, an IACUC and veterinarian recommended inhalation anesthetic, isoflurane, (Butler Schein; 029405) was used to sedate the animal. Once anesthetized, $2 \mathrm{~mm}$ terminal segment of tail was removed with a sterile scissors. Hemostasis was achieved using a silver nitrate applicator stick (Butler Schein; 005383) and potential pain and discomfort were alleviated by applying bupivacaine hydrochloride in sterile isotonic solution (Sigma B5274; $2.5 \mu \mathrm{g} / \mathrm{ml}$ ) locally to the excision site for long-acting pain management. Postsurgical excision site monitoring occurred for 10 days. The tail biopsy was placed in $250 \mu \mathrm{L}$ of DirectPCR Tail lysis buffer (Viagen 101-T) with $10 \mu \mathrm{L}$ Proteinase K solution (Viagen 501-K) and lysed for $6 \mathrm{~h}$ at $55{ }^{\circ} \mathrm{C}$. The sample was then incubated at $85{ }^{\circ} \mathrm{C}$ for $45 \mathrm{~min}$ and briefly centrifuged. The supernatant containing the genetic material was collected and stored at $-20{ }^{\circ} \mathrm{C}$ for subsequent PCR analysis. The resulting PCR products were separated by gel electrophoresis on to a $1.5 \%$ agarose gel (EMD Millipore OmniPur 2120-OP) for 25 min at 110 volts and subsequently imaged on a Bio-Rad Gel $\operatorname{Doc}^{\text {TM }}$ XR. Confirmation of genotypes for the MT1 $1^{-/-}$/ $\mathrm{MT}^{-/-}$double knockout (MTNR-) mice, the $\mathrm{A} \beta \mathrm{PP}^{\mathrm{swe}}$ / PSEN1dE9 (2xAD) mice and their non-transgenic (NonAD/MTNR+) wild-type counterparts was performed. Subsequently, RNA-Sequencing was performed on mouse frontal cortex and hippocampal samples per previously published protocols [106]. Sequencing was performed on an Illumina HiSeq 2500 and confirmed that no melatonin receptor expression was present in the MTNR- mice, 
while both MT1 and MT2 expression were clearly evident in MTNR+ samples. The RNA-Sequencing data were confirmed by qPCR for both MT1 and MT2 [42]. Primers used for genotyping are listed in Table 1.

\section{Behavioral testing}

Mice were tested in a behavioral battery, which included open field activity, elevated plus maze, rota-rod, platform recognition, Barnes maze, Morris water maze, Probe test, and novel object recognition test. For all behavioral testing, testers were blinded to the animal identification number and their respective genotypes and were only allowed to know the artificial 5-digit alphanumeric scheme created to identify the animals. Behavioral tests were performed during the 12-h dark phase, corresponding to the active phase for mice, under white light conditions from $7 \mathrm{pm}$ to midnight. Video recording and/or computer monitoring was utilized to provide accurate analysis of results at a later date. Behavioral testing was conducted with mice at either 12 months of age (2 cohorts; $n=12-14$ ) or at 15 months of age (1 cohort; $n=$ 6-7). Any mice tested at 15 months of age were also tested at 12 months of age. Animals of all genotypes (2xAD/MTNR+, 2xAD/MTNR-, NonAD/MTNR+, NonAD/MTNR-) and treatments (melatonin, vehicle treated) animals were tested at the same times in the same testing apparatus. In general, NonAD mice did not show vehicle (EtOH) versus MEL treatment differences and are therefore not shown. Any cognitive differences between NonAD/MTNR+ and NonAD/ MTNR- animals have already been described in our previous publication [42].

\section{Sensorimotor and locomotor behavior}

An accelerating Rota-rod treadmill (Med Associates, Inc., St. Albans, VT, USA) was used to assess motor and coordination deficits. In this test, the mouse was placed on a rotating horizontal rod, which was $3.2 \mathrm{~cm}$ in diameter. In each trial, the animal was placed on the rod and allowed to acclimate while the rod rotated at a constant 4 rotations per minute (rpm). Subsequently, the speed was accelerated from 4 to $40 \mathrm{rpm}$. Latency in seconds was recorded when either the mouse dropped to the platform $(16.5 \mathrm{~cm})$ or until 5 min elapsed.

Platform Recognition is a swimming-based sensorimotor task often used to measure the animal's ability to visually identify/recognize a variably placed elevated platform, and its ability to approach and ascend on to the surface of the platform. Specifically, this test was utilized as a means of determining if any animal had visual

Table 1 Gene-specific primers used for qPCR experiments and genotyping

\begin{tabular}{|c|c|c|c|c|}
\hline Gene & Gene-specific Primers 5' - 3' & GenBank\# or Primer ID & Amplicon Size & Anneal Temp \\
\hline \multirow[t]{2}{*}{ SOD1 } & S: ATG GCG ATG AAA GCG GTG TG & NM_011434 & 460 & $59^{\circ} \mathrm{C}$ \\
\hline & AS: GCG CAA TCC CAA TCA CTC CA & & & \\
\hline \multirow[t]{2}{*}{ GPx-1 } & S: ATG TGT GCT GCT CGG CTC TC & NM_008160 & 590 & $60^{\circ} \mathrm{C}$ \\
\hline & AS: TGC TGG GAC AGC AGG GTT TC & & & \\
\hline \multirow[t]{2}{*}{ CAT } & S: AGG TाT GGC CTC ACA AGG AC & NM_009804 & 239 & $58^{\circ} \mathrm{C}$ \\
\hline & AS: GCG GTA GGG ACA GTT CAC AG & & & \\
\hline \multirow[t]{2}{*}{ Nrf2 } & S: AAC GAC AGA AAC CTC CAT CTA C & NM_010902 & 94 & $57^{\circ} \mathrm{C}$ \\
\hline & AS: AGT AAG GCT TTC CAT CCT CAT C & & & \\
\hline \multirow[t]{2}{*}{$\mathrm{Rp} 27$} & S: CCA GGA TAA GGA AGG AAT TCC TCC TG & NM_024277 & 297 & $59^{\circ} \mathrm{C}$ \\
\hline & AS: CCA GCA CCA CAT TCA TCA GAA GG & & & \\
\hline \multirow[t]{3}{*}{ MT1R } & GAG TCC AAG TTG CTG GGC AGT GGA & mMT1R-REV-WT & & $94^{\circ} \mathrm{C}$ \\
\hline & GAA GTT TTC TCA GTG TCC CGC AAT GG & mMT1R-FW-WT & 480 & \\
\hline & CCA GCT CAT TCC TCC ACT CAT GAT CTA & mMT1R-NEOFW-KO & 240 & \\
\hline \multirow[t]{3}{*}{ MT2R } & CCA GGC CCC CTG TGA CTG CCC GGG & mMT2R-FW-WT & & $68^{\circ} \mathrm{C}$ \\
\hline & CCT GCC ACT GAG GAC AGA ACA GGG & mMT2R-REV-WT & 272 & \\
\hline & TGC CCC AAA GGC CTA CCC GCT TCC & mMT2R-NEO-REV & 550 & \\
\hline \multirow[t]{2}{*}{ AßPP } & AGG ACT GAC CAC TCG ACC AG & olMR3610 & 377 & $52^{\circ} \mathrm{C}$ \\
\hline & CGG GGG TCT AGT TCT GCA T & olMR3611 & & \\
\hline \multirow[t]{2}{*}{ Psen 1} & AAT AGA GAA CGG CAG GAG CA & OIMR1644 & 608 & $54^{\circ} \mathrm{C}$ \\
\hline & GCC ATG AGG GCA CTA ATC AT & OIMR1645 & & \\
\hline \multirow[t]{2}{*}{ Pos Ctrl } & CTA GGC CAC AGA ATT GAA AGA TCT & OIMR7338 & 324 & $54^{\circ} \mathrm{C}$ \\
\hline & GTA GGT GGA AAT TCT AGC ATC ATC C & olMR7339 & & \\
\hline
\end{tabular}


deficits that could impair their ability to perform in later cognitive tests, as mice on a combined $\mathrm{C} 3 \mathrm{H}$ background can have retinal degeneration. The test was conducted in a pool that measured $88 \mathrm{~cm}$ in diameter and $21 \mathrm{~cm}$ deep and was separated into four equal quadrants by lines suspended above the pool. The temperature of the water was held at $26{ }^{\circ} \mathrm{C}$. A $9 \mathrm{~cm}$ circular platform with a prominent black ensign attached was raised $0.8 \mathrm{~cm}$ above the surface of the water. The platform had a textured surface to aid the mouse in climbing onto the surface and to encourage the mouse to stay on the platform. A $61 \mathrm{~cm}$ high circular barrier was placed around the pool to lessen the escape of the mice. The mice were given four, 60-s maximum trials per day for four days. On each day, the first two trials were consecutive and were separated by a 30-min gap before the next two consecutive trials were performed. The mice began each trial facing the wall of the pool in the same quadrant for each trial for that particular day. The platform was placed in a different quadrant at the start of each day and the mice were started from a different quadrant than the previous day. For each trial, the escape latency was recorded in seconds, concluding when the mouse obtained the platform. A 30-s stay on the platform between consecutive trials was encouraged. A full $60 \mathrm{~s}$ was recorded for any animal that did not obtain the platform and the mouse was gently guided towards the platform and encouraged to remain on the platform for $30 \mathrm{~s}$. During the 30-min gap between consecutive trials and after daily testing, the mice were washed and placed under warming lamps to dry. For statistical analysis, escape latencies were averaged for the first two trials and the second two trials per day.

An Open Field activity test was used to measure exploratory behavior and general activity. The mice were individually placed into an open field box $(45 \mathrm{~cm}$ long $x$ $43.9 \mathrm{~cm}$ wide $\times 30 \mathrm{~cm}$ high). The area was divided into a $4 \times 4$ grid (16 squares) with each square measuring $11.8 \mathrm{~cm} \times 11.2 \mathrm{~cm}$. Mice were given one 5 -min trial in which they were free to move around the box. Activity was scored as the number of line crossings by the mouse during the trial. A line crossing was defined as all four limbs entering into a new square.

\section{Anxiety behavior}

To assess anxiety, animals were evaluated using a nearinfrared (NIR) backlit Elevated Plus Maze (EPM; Med Associates, Inc., St. Albans, VT, USA) consisting of an elevated plus-shaped maze with two opposite open arms $(50 \mathrm{~cm} \times 10 \mathrm{~cm})$ and two opposite closed arms $(50 \mathrm{~cm} \times$ $10 \mathrm{~cm}$ with $40 \mathrm{~cm}$ walls). The tests were conducted with NIR backlight for animal tracking. The task was initiated by placing the test subject into the center of the maze facing an open arm. Activity was monitored via a mounted overhead camera and video tracking system for a $5 \mathrm{~min}$ period. Entries into each arm, and the time spent in open arms, closed arms, and center of maze were evaluated.

\section{Cognitive behavior}

The Barnes Maze (Med Associates, Inc., St. Albans, VT, USA) is a type of delayed match-to-place experiment used to assess spatial/reference learning and memory. Visual objects arranged around the maze served as spatial cues. The maze surface was $121.8 \mathrm{~cm}$ in diameter and $140.2 \mathrm{~cm}$ high with 40 equally spaced holes on the periphery of the surface. A dark box filled with bedding was positioned under one of the holes on the platform to allow the mouse to escape from aversive stimuli. Each mouse was assigned a specific unique escape hole for the duration of the experiment. For each trial, the mouse was placed in the center of the platform facing away from its target escape hole. The aversive stimuli included one high-intensity fan blowing at the level of the platform and two 120-watt flood lamps hung from the ceiling near to and aimed at the platform. Each mouse was given one 600-s trial per day for 8 days and the escape latency in seconds was recorded for each trial. A full $600 \mathrm{~s}$ was recorded for any animal that did not find its target escape hole during a trial.

For the Morris Water Maze, the mice must adopt a spatial learning strategy rather than a recognition strategy used in the platform recognition test. All of the equipment was set up the same as in the platform recognition with a few exceptions. A circular platform without an ensign was placed $1.5 \mathrm{~cm}$ below the surface of the water, which was at $7.8 \mathrm{~cm}$ high. The test was run for 6 consecutive days. The platform remained in the same quadrant for each day of the testing. During the training phase (first 5 days) mice were given 4 successive $60 \mathrm{~s}$ trials per day. The mice were started from a different quadrant in each of the trials. The same quadrant start pattern was used across the 5 days of testing. Latency to find the platform (a maximum of $60 \mathrm{~s}$ ) was recorded for each trial and the four daily trials were averaged for statistical analysis. If a mouse did not find the platform in the $60 \mathrm{~s}$ allowed they were gently guided towards the platform. Once a mouse was on the platform they were allowed to sit for $30 \mathrm{~s}$. If a mouse found the platform by itself and chose to jump off a new trial began. Animals that did not find the platform were given a latency score of $60 \mathrm{~s}$. The Probe Test was the second phase of the experiment and was conducted on day 6. During this phase, the platform was removed and the mice were started from the quadrant opposite of the platform quadrant. The percentage of time spent swimming in each quadrant, including the goal quadrant (which previously held the platform) was recorded. 
The tendency of mice to interact more with a novel object than with a familiar object has been used as a method to study learning and memory [107]. The NovelObject Recognition task (NORT) was performed in a small, opaque open field box $(36 \mathrm{~cm}$ long by $32 \mathrm{~cm}$ wide by $29 \mathrm{~cm}$ high). On the day before the experimental sessions, animals were habituated to the experimental room and NORT chamber for $10 \mathrm{~min}$. Twenty-four hours later, mice were given $10 \mathrm{~min}$ to interact in the testing chamber with two-identical objects. The animal was removed from the apparatus and given a 1-h training-to-testing interval. One of the now familiar objects was replaced with a novel object, which was previously tested for comparable object manipulability and complexity interactions. The mouse was again placed into the testing chamber and allowed to interact freely with the familiar and novel objects for $5 \mathrm{~min}$. The familiar and novel objects were placed on opposite sides of the testing chamber for each trial and the entire testing apparatus was thoroughly cleaned with $70 \%$ ethanol between each subject. The amount of time spent at both familiar and novel objects were determined via video analysis using a "within object area" scoring method. An animal was scored as interacting with the object when its nose was in contact with the object or directed at the object within $\leq 2 \mathrm{~cm}$. Time spent standing, sitting, or leaning on the secured object was not scored as object interaction.

\section{Tissue collection for immunohistochemistry}

All mice were euthanized by sterile intraperitoneal overdose injection of ketamine (Butler Schein; $100 \mathrm{mg} / \mathrm{kg}$ ) and xylazine (Vedco; $10 \mathrm{mg} / \mathrm{kg}$ ) and transcardially perfused first by $0.9 \%$ sterile saline, followed by $4 \%$ paraformaldehyde (PFA). Whole brains were removed and placed into $15 \mathrm{ml}$ of the same PFA fixative used for perfusion for $24 \mathrm{~h}$ at $4{ }^{\circ} \mathrm{C}$. Brains were then placed into autoclaved $30 \%$ sucrose solution at $4{ }^{\circ} \mathrm{C}$ until the brains sank. They were then sectioned into $40 \mu \mathrm{m}$ thick coronal slices and placed into a cryoprotectant solution [108] at $-20{ }^{\circ} \mathrm{C}$ until they were examined by immunohistochemistry.

\section{Immunohistochemistry}

Brain sections were removed from the cryoprotectant solution and washed at room temperature (RT) 3 times for $10 \mathrm{~min}$ in $0.1 \mathrm{M}$ phosphate-buffed saline (PBS) with $0.1 \%$ Triton X-100 (PBSX), followed by a 15-min incubation in $1 \% \mathrm{H}_{2} \mathrm{O}_{2}$ (prepared right before use) and then washed an additional 3 times in PBSX. Slices were then blocked at RT for $60 \mathrm{~min}$ in $1 \%$ normal goat serum (NGS), and incubated in PBS containing $0.4 \%$ Triton X100, NGS, and rabbit anti-human amyloid-beta (A $\beta$; Cell Signaling \#2454) primary antibody for $18 \mathrm{~h}$ at $4{ }^{\circ} \mathrm{C}$. Initial antibody titration occurred at the following dilutions:
1:1 K, 1:3 K, 1:6 K, 1:10 K, and 1:30 K after which 1:6 K was chosen for the best signal to noise ratio. Tissues were washed in PBSX 3 times for $10 \mathrm{~min}$ and treated for $2 \mathrm{~h}$ at RT in PBS with $0.4 \%$ Triton X-100 and NGS with a biotinylated goat anti-rabbit secondary antibody (Vector Laboratories, Burlingame, CA, USA) and again, rinsed 3 times in PBSX for 10 min each. Next, they were transferred to an avidin/biotin solution made $30 \mathrm{~min}$ prior with a Vectastain Elite ABC Kit Standard (Vector Labs) in PBS containing $0.4 \%$ Triton X-100 for $60 \mathrm{~min}$ at RT. Slices were washed twice more in 10-min PBSX washes, followed by a 5 -min rinse in sodium acetate buffer ( $\mathrm{pH}$ 7.5-7.6). Sections were processed for exactly $20 \mathrm{~min}$ at $\mathrm{RT}$ in a nickel-diaminobenzidine (Ni-DAB) solution, prepared from previously made aliquots of $\mathrm{NiSO}_{4}$ and DAB solution, sodium acetate, and $\mathrm{H}_{2} \mathrm{O}_{2}$, followed by another 5 -min sodium acetate buffer rinse. Before the slices were mounted on slides, they had 2 final 10-min PBS rinses and allowed to dry. On the following day, the dehydration process included rinses for 1 min each in the following: distilled $\mathrm{H}_{2} \mathrm{O} ; 50 \%$ ethanol; $75 \%$ ethanol; $95 \%$ ethanol; $2100 \%$ ethanol rinses. The slides were left to air dry for $1 \mathrm{~min}$ before two 5-min washes of Histo-clear (National Diagnostics). Slides were cover-slipped with DPX (distyrene, a plasticizer, and xylene; Electron Microscopy Services, Hatfield, PA, USA) mounting medium and examined under light microscopy with an Olympus MVXIO microscope. Percent area with positive $A \beta$ plaque load was analyzed with Fiji (Fiji is Just ImageJ) software [109].

\section{Blood plasma collection and ELISA for human $A \beta_{1-40}$ and $A \beta_{1-42}$}

Mouse blood plasma was collected for quantitative determination of human $A \beta_{1-40}$ and human $A \beta_{1-42}$ peptides using a solid phase sandwich Enzyme LinkedImmuno-Sorbent Assay (ELISA; Invitrogen Cat\# KHB3481, KHB3441). Blood collection occurred between the hours of 10 am and $1 \mathrm{pm}$. Mice were anesthetized with isoflurane and blood was collected via a puncture to the vascular bed at the back of the jaw where the orbital veins, the submandibular veins, and the other veins draining the facial area coalesce to form the jugular vein. The exuding droplets of blood $(\sim 0.3-$ $0.4 \mathrm{ml}$ ) were collected into an EDTA tube, after which, a sterile gauze compress was applied to the puncture site for $20 \mathrm{~s}$. This rapid blood collection method is more humane than retro-orbital or cardiac puncture, leaving the animals unaffected with no signs of distress [110]. Whole blood was centrifuged at $2000 \mathrm{~g}$ for $3 \mathrm{~min}$ to separate the plasma, which was stored at $-80{ }^{\circ} \mathrm{C}$ until processed by ELISA according to the manufacturer's protocol. 


\section{Tissue collection for oxygen consumption assay and transcript analysis}

All mice were euthanized by sterile intraperitoneal overdose injection of ketamine (Butler Schein; $100 \mathrm{mg} / \mathrm{kg}$ ) and xylazine (Vedco; $10 \mathrm{mg} / \mathrm{kg}$ ), followed by transcardial $0.9 \%$ sterile saline perfusion. Brains were quickly removed and placed on an ice-cold plate for dissection. The brain was initially bisected along the sagittal plane and the left hemisphere was dissected for hippocampus, striatum, and frontal cortex. The dissected samples were then flash frozen for subsequent analysis. The right hemisphere was similarly dissected and preserved in QIAGEN RNAlater ${ }^{\circ}$ RNA stabilization reagent for later mRNA analysis by qPCR.

\section{Cytochrome $\mathrm{C}$ oxidase assay}

Cytochrome c oxidase activity was performed using a standard polarographic method similarly as described in [111]. Specifically, the striatum from 13 month old mice was dissected out, frozen, thawed, diced into cubes, and placed into a dounce glass homogenizer along with $2.5 \mathrm{ml}$ of ice cold isotonic buffer $(7.5 \mathrm{mM}$ sucrose, $0.1 \%$ BSA, $20 \mathrm{mM}$ HEPES, $1 \mathrm{mM}$ EGTA, $215 \mathrm{mM}$ mannitol, pH 7.2). Homogenization was performed in a dounce tissue homogenizer using four strokes with a tight fitting pestle and then the suspension was spun down at 13000 $\times g$ for $5 \mathrm{~min}$ at $4{ }^{\circ} \mathrm{C}$. The supernatant was removed and the pellet was resuspended in $150 \mu \mathrm{l}$ of the ice-cold isotonic buffer above with the addition of $1 \mathrm{mM} \mathrm{n}$-dodecyl$\beta$-D-maltoside. Thirty-five $\mu \mathrm{l}$ of the solubilized heavy membrane fraction was transferred into a respiratory chamber (MT200A, Strathkelvin Instruments) containing $315 \mu \mathrm{l}$ of buffer with $125 \mathrm{mM} \mathrm{KCl}, 1 \mu \mathrm{M}$ FCCP, $50 \mu \mathrm{M}$ cytochrome c, $2 \mathrm{mM}$ ascorbate, $1 \mu \mathrm{M}$ antimycin A, $5 \mathrm{mM}$ tetramethylphenylenediamine (TMPD), $2.5 \mathrm{mM}$ phosphate, and $20 \mathrm{mM}$ HEPES, $\mathrm{pH}$ 7.2. The protein concentration in the respiratory chamber was roughly $2 \mathrm{mg} /$ $\mathrm{mL}$. The rate of oxygen consumption was obtained using a Clark oxygen electrode. After $90 \mathrm{~s}, 700 \mu \mathrm{M} \mathrm{KCN}$ was added to obtain a non-cytochrome c oxidase rate of oxygen consumption, which was subtracted off. The protein concentration was determined by a BCA protein assay (Pierce) and the respiratory rate was normalized to protein concentration.

\section{Isolation of mouse brain mRNA and real-time qPCR}

Total cellular RNA was extracted from homogenized frontal cortices with QIAShredder ${ }^{\text {Tux }}$ columns in QIAGEN's buffer RLT and $\beta$-mercaptoethanol in a 100:1 ratio followed by processing with the QIAGEN $^{\circ}$ RNeasy $\mathrm{Kit}^{\circ}$ and DNase Set treatment kits according to the manufacturer's protocols. The RNA concentration was measured with a Thermo Scientific Nanodrop photometer. For analysis of transcript levels, one $\mu \mathrm{g}$ of total RNA was reverse-transcribed to cDNA by means of the Bio-rad iScript ${ }^{\mathrm{TM}}$ reverse-transcription system. Amplification of the cDNA was performed on a Bio-Rad CFX96 Touch $^{\text {ma }}$ Real-Time PCR Detection System using the iQ SYBR ${ }^{\circ}$ Green Supermix protocol according to the manufacturer specifications. The following thermal cycling parameters were used: initial heat activation of the DNA-polymerase was performed at $95{ }^{\circ} \mathrm{C}$ for $5 \mathrm{~min}$. Thereafter, 40 cycles of $95{ }^{\circ} \mathrm{C}(10 \mathrm{~s}), 57-60.5^{\circ} \mathrm{C}(10 \mathrm{~s})$ and $72{ }^{\circ} \mathrm{C}(30 \mathrm{~s})$ were run. The primer sequences and annealing temperatures for the gene transcripts that were analyzed are listed in Table 1.

\section{Statistics}

All calculations, comparisons and statistical analysis were performed using GraphPad Prism version 6.0a software for Mac OS X (GraphPad Software, La Jolla, California, USA, www.graphpad.com). The values shown on the graphs represent the means \pm S.E.M. from independent experiments. Behavioral tests comparing differences between genotypes and treatments were computed with a 2-way ANOVA followed by Bonferroni's multiple comparison of means. The Kaplan-Meier survival curve was analyzed with a Wilcoxon-Gehan-Breslow log-rank test (chi square). Tests conducted with multiple trials or time points were analyzed with a 2-way ANOVA for repeated measures and followed by the Bonferroni test for post hoc comparison. Statistical values reaching $p \leq 0.05$ were considered significant.

\section{Abbreviations}

2xAD: Mice with double Alzheimer mutation (AßPPPswe/PSEN1dE9); $A \beta$ : Amyloid-beta; $A \beta P P^{\text {swe. }}$ : Amyloid-beta precursor protein, human Swedish mutation; AD: Alzheimer's disease; C3B6: Mice with a combination C3H/He and C57BL/6 background; CAT: Catalase; CDNA: Complementary deoxyribonucleic acid; CNS: Central nervous system; DD: Dark-dark or constant dark; DNA: Deoxyribonucleic acid; DPX: Distyrene, a plasticizer, and xylene; EPM: Elevated plus maze; GPX-1: Glutathione peroxidase 1; HEPES: 2[4-(2-hydroxyethyl)piperazin-1-yl]ethanesulfonic acid; HPC: Hippocampus; IHC: Immunohistochemistry; MEL: Melatonin; mRNA: Messenger ribonucleic acid; MTNR: Melatonin receptor; MTNR-: Mice without melatonin receptors; MTNR+: Mice with melatonin receptors; MTNR1a or MT1: Melatonin receptor type 1; MTNR1b or MT2: Melatonin receptor type 2; MWM: Morris water maze; NGS: Normal Goat Serum; Ni-DAB: Nickel-diaminobenzidine; NonAD: Non-Alzheimer control animals; NORT: Novel object recognition task; Nrf2: Nuclear factor erythroid 2-related factor 2; PBS: Phosphate-buffered saline; PBSX: Phosphate-buffered saline with 0.1 \% Triton X-100; PCR: Polymerase chain reaction; PFA: Paraformaldehyde; PGK: Phosphoglycerate kinase promoter; PS1 or Psen1: Presenilin 1; qPCR: Quantitative polymerase chain reaction; SDSPAGE: Sodium dodecyl sulfate-polyacrylamide gel electrophoresis; SOD1: Superoxide dismutase 1.

\section{Competing interests}

The authors declare that they have no competing interests.

\section{Authors' contributions}

GM, JO, VD, and PB designed the experiments; GM and VD performed the experiments, analyzed the data and performed statistical analysis; GM, JO, VD, and PB wrote and approved the final manuscript. 


\section{Acknowledgements}

The authors thank the following for their respective contributions: Dr. David Weaver for the mice; Crupa Kurien, Stephen Bell, Tam-Anh Phan, and Sandra Zivkovic for assisting with the COX assays; Michelle de Jesus, Kathryn Whitten, Ziyan Song, Juno Lee, Andrew Blanke, Blake Davis, Joseph Volpe, Haley Powell, Kyle Borodunovich, Kaitlin Jaquett, and Lindsay Kiernan for assistance with behavioral testing, qPCR, blood/tissue collections, and immunohistochemistry; Philip O'Neal for equipment design; Charles Badland for assistance in generating figures; Georgia Platt for manuscript formatting; and Dr. Richard Nowakowski for his continuing support. This work was supported by grants to J. Olcese from the Florida State University Council on Faculty Research and Creativity, and the FSU College of Medicine (Division of Research).

\section{Author details}

Department of Biomedical Sciences, College of Medicine, Florida State University Program in Neuroscience, 1115 West Call Street, Tallahassee, FL 32306, USA. ²Department of Cell Biology, Microbiology, and Molecular Biology, University of South Florida, 4202 East Fowler Avenue, ISA2015, Tampa, FL 33620, USA.

\section{Received: 17 April 2015 Accepted: 30 June 2015}

\section{Published online: 11 July 2015}

\section{References}

1. Rodda J, Morgan S, Walker Z. Are cholinesterase inhibitors effective in the management of the behavioral and psychological symptoms of dementia in Alzheimer's disease? A systematic review of randomized, placebocontrolled trials of donepezil, rivastigmine and galantamine. Int Psychogeriatr. 2009;21(5):813-24.

2. Lane RF, Shineman DW, Steele JW, Lee LB, Fillit HM. Beyond Amyloid: The future of Therapeutics for Alzheimer's Disease. Adv Pharmacol. 2012;64:213-71.

3. Mullane K, Williams M. Alzheimer's therapeutics: continued clinical failures question the validity of the amyloid hypothesis - but what lies beyond? Biochem Pharmacol. 2013;85(3):289-305

4. Macchi MM, Bruce JM. Human pineal physiology and functional significance of melatonin. Front Neuroendocrinol. 2004;25(3-4):177-95.

5. Dubocovich ML, Delagrange $P$, Krause DN, Sugden D, Cardinali DP, Olcese J. International Union of Basic and Clinical Pharmacology. LXXV. Nomenclature, classification, and pharmacology of G protein coupled melatonin receptors. Pharmacol Rev. 2010;62(3):343-80.

6. Reiter RJ, Tan DX, Korkmaz A, Rosales-Corral SA. Melatonin and stable circadian rhythms optimize maternal, placental, fetal physiology. Hum Reprod Update. 2014;20(2):293-307.

7. Arendt J, Skene DJ. Melatonin as a chronobiotic. Sleep Med Rev. 2005;9(1):25-39.

8. Wu YH, Feenstra MG, Zhou JN, Liu RY, Toranõ JS, Van Kan HJ, et al. Molecular changes underlying reduced pineal melatonin levels in Alzheimer disease: alterations in preclinical and clinical stages. J Clin Endocrinol Metab. 2003:88(12):5898-906.

9. Zhou JN, Liu RY, Kamphorst W, Hofman MA, Swaab DF. Early neuropathological Alzheimer's changes in aged individuals are accompanied by decreased cerebrospinal fluid melatonin levels. J Pineal Res. 2003;35(2):125-30.

10. Brusco LI, Márquez M, Cardinali DP. Melatonin treatment stabilizes chronobiologic and cognitive symptoms in Alzheimer's disease. Neuro Endocrinol Lett. 2000;21(1):39-42.

11. Furio AM, Brusco L, Cardinali DP. Possible therapeutic value of melatonin in mild cognitive impairment: a retrospective study. J Pineal Res. 2007;43(4):404-9.

12. Brusco L, Márquez M, Cardinali DP. Monozygotic twins with Alzheimer's disease treated with melatonin: Case report. J Pineal Res. 1998;25(4):260-3.

13. Korkmaz A, Reiter RJ, Topal T, Manchester LC, Oter S, Tan DX. Melatonin: An established antioxidant worthy of use in clinical trials. Mol Med. 2009;15:43-50.

14. Bonnefont-Rousselot D, Collin F. Melatonin: action as antioxidant and potential applications in human disease and aging. Toxicology. 2010;278(1):55-67.

15. Yeleswaram K, McLaughlin LG, Knipe JO, Schabdach D. Pharmacokinetics and oral bioavailability of exogenous melatonin in preclinical animal models and clinical implications. J Pineal Res. 1997;22(1):45-51.

16. Pappolla M, Bozner P, Soto C, Shao H, Robakis NK, Zagorski M, et al. Inhibition of Alzheimer beta-fibrillogenesis by melatonin. J Biol Chem. 1998;273(13):7185-8
17. Poeggeler B, Miravalle L, Zagorski MG, Wisniewski T, Chyan YJ, Zhang Y, et al. Melatonin reverses the profibrillogenic activity of apolipoprotein E4 on the Alzheimer amyloid Abeta peptide. Biochemistry. 2001;40(49):14995-5001.

18. Cheng $X$, van Breemen RB. Mass spectrometry-based screening for inhibitors of beta-amyloid protein aggregation. Anal Chem. 2005;77(21):7012-5.

19. Skribanek Z, Baláspiri L, Mák M. Interaction between synthetic amyloid-betapeptide (1-40) and its aggregation inhibitors studied by electrospray ionization mass spectrometry. J Mass Spectrom. 2001;36(11):1226-9.

20. Fraser PE, Nguyen JT, Surewicz WK, Kirschner DA. pH-dependent structural transitions of Alzheimer amyloid peptides. Biophys J. 1991;60(5):1190-201.

21. Jang MH, Jung SB, Lee MH, Kim CJ, Oh YT, Kang I, et al. Melatonin attenuates amyloid beta25-35-induced apoptosis in mouse microglial BV2 cells. Neurosci Lett. 2005;380(1-2):26-31.

22. Gunasingh MJ, Philip JE, Ashok BS, Kirubagaran R, Jebaraj WC, Davis GD, et al. Melatonin prevents amyloid protofibrillar induced oxidative imbalance and biogenic amine catabolism. Life Sci. 2008;83(3-4):96-102.

23. Olcese JM, Cao C, Mori T, Mamcarz MB, Maxwell A, Runfeldt MJ, et al. Protection against cognitive deficits and markers of neurodegeneration by long-term oral administration of melatonin in a transgenic model of Alzheimer disease. J Pineal Res. 2009;47(1):82-96.

24. Matsubara E, Bryant-Thomas T, Pacheco Quinto J, Henry TL, Poeggeler B, Herbert D, et al. Melatonin increases survival and inhibits oxidative and amyloid pathology in a transgenic model of Alzheimer's disease. $J$ Neurochem. 2003;85(5):1101-8.

25. Peng CX, Hu J, Liu D, Hong XP, Wu YY, Zhu LQ, et al. Disease-modified glycogen synthase kinase-3 $\beta$ intervention by melatonin arrests the pathology and memory deficits in an Alzheimer's animal model. Neurobiol Aging 2013:34(6):1555-63.

26. Quinn J, Kulhanek D, Nowlin J, Jones R, Pratico D, Rokach J, et al. Chronic melatonin therapy fails to alter amyloid burden or oxidative damage in old Tg2576 mice: implications for clinical trials. Brain Res. 2005;1037(1-2):209-13.

27. Guerrero J, Reiter R. Melatonin-immune system relationships. Curr Top Med Chem. 2002;2(2):167-79.

28. Caballero B, Vega-Naredo I, Sierra V, Huidobro-Fernández C, Soria-Valles C, De Gonzalo-Calvo D, et al. Favorable effects of a prolonged treatment with melatonin on the level of oxidative damage and neurodegeneration in senescence-accelerated mice. J Pineal Res. 2008;45(3):302-11.

29. Hardeland R, Cardinali DP, Brown GM, Pandi-Perumal SR. Melatonin and brain inflaming. Prog Neurobiol. 2015;127-128C:46-63.

30. Rosales-Corral S, Tan DX, Reiter RJ, Valdivia-Velázquez M, Martínez-Barboza G, Acosta-Martínez JP, et al. Orally administered melatonin reduces oxidative stress and proinflammatory cytokines induced by amyloid-beta peptide in rat brain: a comparative, in vivo study versus vitamin $\mathrm{C}$ and $\mathrm{E}$. J Pineal Res. 2003:35(2):80-4

31. Mayo JC, Sainz RM, Tan DX, Hardeland R, Leon J, Rodriguez C, et al. Antiinflammatory actions of melatonin and its metabolites, N1-acetyl-N2-formy 5-methoxykynuramine (AFMK) and N1-acetyl-5-methoxykynuramine (AMK), in macrophages. J Neuroimmunol. 2005;165(1-2):139-49.

32. Srinivasan V, Smits M, Spence W, Lowe AD, Kayumov L, Pandi-Perumal SR, et al. Melatonin in mood disorders. World J Biol Psychiatry. 2006;7(3):138-51.

33. Dragicevic N, Copes N, O'Neal-Moffitt G, Jin J, Buzzeo R, Mamcarz M, et al. Melatonin treatment restores mitochondrial function in Alzheimer's mice: a mitochondrial protective role of melatonin membrane receptor signaling. J Pineal Res. 2011;51(1):75-86.

34. Li XC, Wang ZF, Zhang JX, Wang Q, Wang JZ. Effect of melatonin on calyculin A-induced tau hyperphosphorylation. Eur J Pharmacol. 2005:510(1-2):25-30.

35. Kaur C, Sivakumar V, Yong Z, Lu J, Foulds WS, Ling EA. Blood-retinal barrier disruption and ultrastructural changes in the hypoxic retina in adult rats: the beneficial effect of melatonin administration. J Pathol. 2007;212(4):429-39.

36. Letechipía-Vallejo G, López-Loeza E, Espinoza-González V, González-Burgos I, Olvera-Cortés ME, Moralí G, et al. Long-term morphological and functional evaluation of the neuroprotective effects of post-ischemic treatment with melatonin in rats. J Pineal Res. 2007;42(2):138-46.

37. García-Chávez D, González-Burgos I, Letechipía-Vallejo G, López-Loeza E, Moralí $\mathrm{G}$, Cervantes M. Long-term evaluation of cytoarchitectonic characteristics of prefrontal cortex pyramidal neurons, following global cerebral ischemia and neuroprotective melatonin treatment, in rats. Neurosci Lett. 2008;448(1):148-52.

38. Domínguez-Alonso A, Ramirez-Rodríguez G, Benítez-King G. Melatonin increases dendritogenesis in the hilus of hippocampal organotypic cultures. J Pineal Res. 2012;52(4):427-36. 
39. McKenna JT, Christie MA, Jeffrey BA, McCoy JG, Lee E, Connolly NP, et al. Chronic ramelteon treatment in a mouse model of Alzheimer's disease. Arch Ital Biol. 2012;150(1):5-14.

40. Baño Otalora B, Popovic N, Gambini J, Popovic M, Viña J, Bonet-Costa V, et al. Circadian system functionality, hippocampal oxidative stress and spatial memory in the APPswe/PS1dE9 transgenic model of Alzheimer disease: effects of melatonin or ramelteon. Chronobiol Intl. 2012;29(7):822-34.

41. Mathes AM, Kubulus D, Waibel L, Weiler J, Heymann P, Wolf B, et al. Selective activation of melatonin receptors with ramelteon improves liver function and hepatic perfusion after hemorrhagic shock in rat. Crit Care Med. 2008;36:2863-70

42. O'Neal-Moffitt G, Pilli J, Kumar SS, Olcese JM. Genetic deletion of MT1/MT2 melatonin receptors enhances murine cognitive and motor performance. Neuroscience. 2014;277:506-21.

43. Yuede CM, Zimmerman SD, Dong H, Kling MJ, Bero AW, Holtzman DM, et al. Effects of voluntary and forced exercise on plaque deposition, hippocampal volume, and behavior in the Tg2576 mouse model of Alzheimer's disease. Neurobiol Dis. 2009;35(3):426-32

44. Zhang R, Xue G, Wang S, Zhang L, Shi C, Xie X. Novel object recognition as a facile behavior test for evaluating drug effects in AßPP/PS1 Alzheimer's disease mouse model. J Alzheimers Dis. 2012;31(4):801-12.

45. Petrosillo G, De Benedictis V, Ruggiero FM, Paradies G. Decline in cytochrome c oxidase activity in rat-brain mitochondria with aging. Role of peroxidized cardiolipin and beneficial effect of melatonin. J Bioenerg Biomembr. 2013;45(5):431-40.

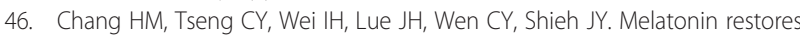
the cytochrome oxidase reactivity in the nodose ganglia of acute hypoxic rats. J Pineal Res. 2005;39(2):206-14

47. Dragicevic N, Mamcarz M, Zhu Y, Buzzeo R, Tan J, Arendash GW, et al. Mitochondrial amyloid-beta levels are associated with the extent of mitochondrial dysfunction in different brain regions and the degree of cognitive impairment in Alzheimer's transgenic mice. J Alzheimers Dis. 2010;20 Suppl 2:S535-550.

48. Du H, Guo L, Yan S, Sosunov AA, McKhann GM, Yan SS. Early deficits in synaptic mitochondria in an Alzheimer's disease mouse model. Proc Natl Acad Sci U S A. 2010:107(43):18670-5.

49. Crouch PJ, Blake R, Duce JA, Ciccotosto GD, Li QX, Barnham KJ, et al Trounce IA Copper-dependent inhibition of human cytochrome c oxidase by a dimeric conformer of amyloid-beta1-42. J Neurosci. 2005;25:672-9.

50. Feng Z, Chang Y, Cheng Y, Zhang BL, Qu ZW, Qin C, et al. Melatonin alleviates behavioral deficits associated with apoptosis and cholinergic system dysfunction in the APP 695 transgenic mouse model of Alzheimer's disease. J Pineal Res. 2004:37(2):129-36.

51. Feng Z, Qin C, Chang Y, Zhang JT. Early melatonin supplementation alleviates oxidative stress in a transgenic mouse model of Alzheimer's disease. Free Radic Biol Med. 2006:40(1):101-9.

52. 52 García-Mesa Y, Giménez-Liort L, López LC, Venegas C, Cristòfol R, Escames G, Acuña-Castroviejo D, Sanfeliu C. Melatonin plus physical exercise are highly neuroprotective in the $3 \times \mathrm{Tg}-\mathrm{AD}$ mouse. Neurobiol Aging. 2012;33(6):1124.e13-29.

53. Rosales-Corral S, Acuña-Castroviejo D, Tan DX, López-Armas G, Cruz-Ramos J, Munoz R, et al. Accumulation of exogenous amyloid-beta peptide in hippocampal mitochondria causes their dysfunction: a protective role for melatonin. Oxid Med Cell Longev. 2012. doi:10.1155/2012/843649.

54. Volianskis A, Køstner R, Mølgaard M, Hass S, Jensen MS. Episodic memory deficits are not related to altered glutamatergic synaptic transmission and plasticity in the CA1 hippocampus of the APPswe/PS1 $\triangle$ E9-deleted transgenic mice model of $\beta$-amyloidosis. Neurobiol Aging. 2010;31(7):1173-87.

55. Papp M, Litwa E, Gruca P, Mocaër E. Anxiolytic-like activity of agomelatine and melatonin in three animal models of anxiety. Behav Pharmacol. 2006;17(1):9-18

56. Crupi R, Mazzon E, Marino A, La Spada G, Bramanti P, Cuzzocrea S, et al. Melatonin treatment mimics the antidepressant action in chronic corticosterone-treated mice. J Pineal Res. 2010;49(2):123-9.

57. Srinivasan V, Pandi-Perumal SR, Cardinali DP, Poeggeler B. Hardeland R Melatonin in Alzheimer's disease and other neurodegenerative disorders. Behav Brain Funct. 2006;2:15.

58. Caumo W, Levandovski R, Hidalgo MP. Preoperative anxiolytic effect of melatonin and clonidine on postoperative pain and morphine consumption in patients undergoing abdominal hysterectomy: a double-blind, randomized, placebo-controlled study. J Pain. 2009;10(1):100-8.
59. Ochoa-Sanchez R, Rainer Q, Comai S, Spadoni G, Gedini A, Rivara S, et al. Anxiolytic effects of the melatonin MT(2) receptor partial agonist UCM765: comparison with melatonin and diazepam. Prog Neuropsychopharmacol Biol Psychiatry. 2012;39(2):318-25.

60. Di Paolo C, Revert I, Colomina MT, Domingo JL, Gómez M. Chronic exposure to aluminum and melatonin through the diet: Neurobehavioral effects in a transgenic mouse model of Alzheimer disease. Food Chem Toxicol. 2014:69:320-9.

61. Minkeviciene R, Rheims S, Dobszay MB, Zilberter M, Hartikainen J, Fulop L, et al. Amyloid beta-induced neuronal hyperexcitability triggers progressive epilepsy. J Neurosci. 2009;29(11):3453-62.

62. Jankowsky JL, Fadale DJ, Anderson J, Xu GM, Gonzales V, Jenkins NA, et al. Mutant presenilins specifically elevate the levels of the 42 residue beta-amyloid peptide in vivo: evidence for augmentation of a 42-specific gamma secretase. Hum Mol Genet. 2004;13(2):159-70.

63. Jack Jr CR, Knopman DS, Jagust WJ, Petersen RC, Weiner MW, Aisen PS, et al. Trojanowski JQ Tracking pathophysiological processes in Alzheimer's disease: an updated hypothetical model of dynamic biomarkers. Lancet Neurol. 2013;12(2):207-16.

64. Ji Y, Permanne B, Sigurdsson EM, Holtzman DM, Wisniewski T. Amyloid beta40/42 clearance across the blood-brain barrier following intraventricular injections in wild-type apoE knock-out and human apoE3 or E4 expressing transgenic mice. J Alzheimers Dis. 2001;3(1):23-30.

65. Domert J, Rao SB, Agholme L, Brorsson AC, Marcusson J, Hallbeck M, et al. Spreading of amyloid- $\beta$ peptides via neuritic cell-to-cell transfer is dependent on insufficient cellular clearance. Neurobiol Dis. 2014;65:82-92.

66. Shukla M, Htoo HH, Wintachal P, Hernandez F, Dubois C, Postina R, et al. Melatonin stimulates the nonamyloidogenic processing of $\beta A P P$ through the positive transcriptional regulation of ADAM10 and ADAM17. J Pineal Res. 2015;58:151-65.

67. Rodríguez Santiago B, Casademont J, Nunes V. Is there a relation between Alzheimer's disease and defects of mitochondrial DNA? Rev Neurol. 2001;33(4):301-5

68. Parks JK, Smith TS, Trimmer PA, Bennett Jr JP, Parker Jr WD. Neurotoxic Abeta peptides increase oxidative stress in vivo through NMDA receptor and nitric-oxide-synthase mechanisms, and inhibit complex IV activity and induce a mitochondrial permeability transition in vitro. J Neurochem. 2001;76(4):1050-6.

69. Leuner K, Müller WE, Reichert AS. From Mitochondrial Dysfunction to Amyloid beta Formation: Novel Insights into the Pathogenesis of Alzheimer's Disease. Mol Neurobiol. 2012;46:186-93.

70. Manczak M, Anekonda TS, Henson E, Park BS, Quinn J, Reddy PH. Mitochondria are a direct site of A beta accumulation in Alzheimer's disease neurons: implications for free radical generation and oxidative damage in disease progression. Hum Mol Genet. 2006;15(9):1437-49.

71. Navarro A. Mitochondrial enzyme activities as biochemical markers of aging. Mol Aspects Med. 2004;25(1-2):37-48.

72. Gutsaeva DR, Suliman HB, Carraway MS, Demchenko IT, Piantadosi CA. Oxygen-induced mitochondrial biogenesis in the rat hippocampus. Neuroscience. 2006;137(2):493-504.

73. Yoboue ED, Devin A. Reactive oxygen species-mediated control of mitochondrial biogenesis. Int J Cell Biol. 2012. doi:10.1155/2012/403870.

74. López A, García JA, Escames G, Venegas C, Ortiz F, López LC, et al. Melatonin protects the mitochondria from oxidative damage reducing oxygen consumption, membrane potential, and superoxide anion production. J Pineal Res. 2009;46(2):188-98.

75. Song J, Kang SM, Lee KM, Lee JE. The protective effect of melatonin on neural stem cell against LPS-induced inflammation. Biomed Res Int. 2015;2015:854359.

76. Strazielle C, Sturchler-Pierrat C, Staufenbiel M, Lalonde R. Regional brain cytochrome oxidase activity in beta-amyloid precursor protein transgenic mice with the Swedish mutation. Neuroscience. 2003;118(4):1151-63.

77. Poirier GL, Amin E, Good MA, Aggleton JP. Early-onset dysfunction of retrosplenial cortex precedes overt amyloid plaque formation in Tg2576 mice. Neuroscience. 2011;174:71-83.

78. Cuadrado-Tejedor M, Cabodevilla JF, Zamarbide M, Gómez-Isla T, Franco R, Perez-Mediavilla A. Age-related mitochondrial alterations without neuronal loss in the hippocampus of a transgenic model of Alzheimer's disease. Curr Alzheimer Res. 2013;10(4):390-405.

79. Reddy PH, McWeeney S, Park BS, Manczak M, Gutala RV, Partovi D, et al. Gene expression profiles of transcripts in amyloid precursor protein 
transgenic mice: up-regulation of mitochondrial metabolism and apoptotic genes is an early cellular change in Alzheimer's disease. Hum Mol Genet. 2004;13(12):1225-40.

80. Zhu X, Perry G, Moreira PI, Aliev G, Cash AD, Hirai K, et al. Mitochondrial abnormalities and oxidative imbalance in Alzheimer disease. J Alzheimers Dis. 2006;9(2):147-53.

81. Demetrius LA, Magistretti PJ, Pellerin L. Alzheimer's disease: the amyloid hypothesis and the Inverse Warburg effect. Front Physiol. 2015;5:522.

82. Valla J, Schneider LE, Small AM, Gonzalez-Lima F. Quantitative Cytochrome Oxidase Histochemistry: Applications in Human Alzheimer's Disease and Animal Models. Journal of Histotechnology. 2007;30:235-47.

83. Varghese M, Zhao W, Wang J, Cheng A, Qian X, Chaudhry A, et al. Mitochondrial bioenergetics is defective in presymptomatic Tg2576 AD mice. Transl Neurosci. 2011;2(1):1-5.

84. Zhang XM, Xiong K, Cai Y, Cai H, Luo XG, Feng JC, et al. Functional deprivation promotes amyloid plaque pathogenesis in Tg2576 mouse olfactory bulb and piriform cortex. Eur J Neurosci. 2010;31(4):710-21.

85. Rhein V, Song X, Wiesner A, Ittner LM, Baysang G, Meier F, et al. Amyloidbeta and tau synergistically impair the oxidative phosphorylation system in triple transgenic Alzheimer's disease mice. Proc Natl Acad Sci U S A. 2009;106(47):20057-62.

86. Wolf $A B$, Braden BB, Bimonte-Nelson $H$, Kusne $Y$, Young N, Engler-Chiurazz $E$, et al. Broad-based nutritional supplementation in 3xTg mice corrects mitochondrial function and indicates sex-specificity in response to Alzheimer's disease intervention. J Alzheimers Dis. 2012;32(1):217-32.

87. Bobba A, Amadoro G, Valenti D, Corsetti V, Lassandro R. Atlante A (2013) Mitochondrial respiratory chain Complexes I and IV are impaired by betaamyloid via direct interaction and through Complex I-dependent ROS production, respectively. Mitochondrion. 2013:13(4):298-311.

88. Vladimirov YA, Proskurnina EV, Izmailov DY, Novikov AA, Brusnichkin AV, Osipov AN, et al. Mechanism of activation of cytochrome $C$ peroxidase activity by cardiolipin. Biochemistry (Mosc). 2006;71(9):989-97.

89. Hong WK, Han EH, Kim DG, Ahn JY, Park JS, Han BG. Amyloid-beta-peptide reduces the expression level of mitochondrial cytochrome oxidase subunits. Neurochem Res. 2007;32:1483-8.

90. Fukuda R, Zhang H, Kim JW, Shimoda L, Dang CV, Semenza GL. HIFregulates cytochrome oxidase subunits to optimize efficiency of respiration in hypoxic cells. Cell. 2007;129:111-22.

91. Huttemann M, Lee I, Grossman LI, Doan JW, Sanderson TH. Phosphorylation of mammalian cytochrome $\mathrm{c}$ and cytochrome $\mathrm{c}$ oxidase in the regulation of cell destiny: respiration, apoptosis, and human disease. Adv Exp Med Biol. 2012;748:237-64

92. Praticò D, Uryu K, Leight S, Trojanoswki JQ, Lee VM. Increased lipid peroxidation precedes amyloid plaque formation in an animal model of Alzheimer amyloidosis. J Neurosci. 2001;21(12):4183-7.

93. Honda K, Smith MA, Zhu X, Baus D, Merrick WC, Tartakoff AM, et al. Ribosomal RNA in Alzheimer disease is oxidized by bound redox-active iron. J Biol Chem. 2005;280(22):20978-86

94. Resende R, Moreira PI, Proença T, Deshpande A, Busciglio J, Pereira C, et al. Brain oxidative stress in a triple-transgenic mouse model of Alzheimer disease. Free Radic Biol Med. 2008;44(12):2051-7.

95. Kotler M, Rodríguez C, Sáinz RM, Antolín I, Menéndez-Peláez A. Melatonin increases gene expression for antioxidant enzymes in rat brain cortex. J Pineal Res. 1998;24(2):83-9.

96. Mayo JC, Sainz RM, Antoli I, Herrera F, Martin V, Rodriguez C. Melatonin regulation of antioxidant enzyme gene expression. Cell Mol Life Sci. 2002;59(10):1706-13.

97. Subramanian P, Mirunalini S, Pandi-Perumal SR, Trakht I, Cardinali DP. Melatonin treatment improves the antioxidant status and decreases lipid content in brain and liver of rats. Eur J Pharmacol. 2007:571(2-3):116-9.

98. Ding K, Wang H, Xu J, Li T, Zhang L, Ding Y, et al. Melatonin stimulates antioxidant enzymes and reduces oxidative stress in experimental traumatic brain injury: the Nrf2-ARE signaling pathway as a potential mechanism. Free Radic Biol Med. 2014;73C:1-11.

99. Pandi-Perumal SR, BaHammam AS, Brown GM, Spence DW, Bharti VK, Kaur $C$, et al. Melatonin antioxidative defense: therapeutical implications for aging and neurodegenerative processes. Neurotox Res. 2013;23(3):267-300.

100. Liu C, Weaver DR, Jin X, Shearman LP, Pieschi RL, Gribkoff VK, et al. Molecular dissection of two distinct actions of melatonin on the suprachiasmatic circadian clock. Neuron. 1997;19(1):91-102.
101. Jin X, von Gall C, Pieschl RL, Gribkoff VK, Stehle JH, Reppert SM, et al. Targeted disruption of the mouse Mel(1b) melatonin receptor. Mol Cell Biol. 2003;23(3):1054-60.

102. Ebihara S, Marks T, Hudson DJ, Menaker M. Genetic control of melatonin synthesis in the pineal gland of the mouse. Science. 1986;23(4737):491-3.

103. Roseboom PH, Namboodiri MA, Zimonjic DB, Popescu NC, Rodriguez IR, Gastel JA, et al. Natural melatonin 'knockdown' in C57BL/6 J mice: rare mechanism truncates serotonin N-acetyltransferase. Brain Res Mol Brain Res. 1998;63(1):189-97.

104. Kasahara T, Abe K, Mekada K, Yoshiki A, Kato T. Genetic variation of melatonin productivity in laboratory mice under domestication. Proc Nat Acad Sci U S A. 2010;107:6412-7.

105. Reagan-Shaw S, Nihal M, Ahmad N. Dose translation from animal to human studies revisited. FASEB J. 2008;22(3):659-61.

106. Mortazavi A, Williams BA, McCue K, Schaeffer L, Wold B. Mapping and quantifying mammalian transcriptomes by RNA-Seq. Nat Methods. 2008;5(7):621-8

107. Bevins RA, Besheer J. Object recognition in rats and mice: a one-trial nonmatching-to-sample learning task to study 'recognition memory'. Nat Protoc. 2006;1(3):1306-11.

108. Hoffman GE, Le WW, Sita LV. Current Protocols in Neuroscience: The importance of titrating antibodies for immunocytochemical methods. Wiley; 2008. doi:10.1002/0471142301.ns0212s45.

109. Schindelin J, Arganda-Carreras I, Frise E, Kaynig V, Longair M, Pietzsch T, et al. Fiji: an open-source platform for biological-image analysis. Nat Methods. 2012:9(7):676-82.

110. Golde WT, Gollobin P, Rodriguez LL. A rapid, simple, and humane method for submandibular bleeding of mice using a lancet. Lab Anim. 2005;34(9):39-43.

111. Villani G, Attardi G. Polarographic assays of respiratory chain complex activity. Methods Cell Biol. 2007;80:121-33.

\section{Submit your next manuscript to BioMed Central and take full advantage of:}

- Convenient online submission

- Thorough peer review

- No space constraints or color figure charges

- Immediate publication on acceptance

- Inclusion in PubMed, CAS, Scopus and Google Scholar

- Research which is freely available for redistribution 